Article

\title{
Environmental Heat Stress on Indoor Environments in Shallow, Deep and Covered Atrium Plan Form Office Buildings in Tropics
}

\author{
Upendra Rajapaksha \\ University of Moratuwa, Department of Architecture in University of Moratuwa, Moratuwa 10400, Sri Lanka; \\ upendra@uom.lk
}

Received: 4 January 2020; Accepted: 19 February 2020; Published: 22 February 2020

check for updates

\begin{abstract}
Environmental heat stress on buildings through façades contributes to indoor overheating and thus increases demand for energy consumption. The study analyzed the problem, heat gain risk, of modern air-conditioned multi-level office buildings in tropics, for example Colombo. Plan form, orientation, sectional form and envelope were identified and theorized to understand design interventions to reduce the risk of getting heat stress on indoor environments. On-site thermal performance investigations in multi zones of identified three typical built forms, namely; shallow, deep and covered atrium plan forms, quantified the heat stress. Reaching the daytime indoor and surface temperature in peripheral zones of multi-story office buildings during air conditioning "off-mode" up to $38^{\circ} \mathrm{C}-42{ }^{\circ} \mathrm{C}$ was seen as a critical heat stress situation to be addressed through building design. Shading or insulation on façades to control environmental heat gain and manipulation of building section for night ventilation to remove internal heat developed during the daytime are discussed. However, the significance of the plan form depth was found to be a main contributor in dealing with heat transfer to indoor space. Deep plan form was found to be more effective in controlling environmental heat transfer to indoor space across the plan depth.
\end{abstract}

Keywords: heat stress from outside; indoor environments; tropics; multi-level office buildings

\section{Introduction}

Thermal comfort experienced by the building occupants plays a vital role in enhancing climate responsive design. Indoor overheating, in this context, is identified as one major problem. Indoor overheating is a condition where indoor air temperature moves above the upper limits of comfort zone. This can result in thermal discomfort while reducing the productivity of the occupants in buildings with free floating conditions. Further, overheated indoors demand extensive use of mechanical systems for cooling and thus increase in operational energy.

Controlling environmental solar heat gains into buildings due to high levels of ambient air temperature, internal heat generation from occupants and equipment together with enhancing heat escape from indoors determines the thermal balance in buildings [1,2]. Depending on the climate type and usage pattern of buildings, excess heat gain could contribute to indoor overheating [3].

Reducing indoor overheating potential of the building design contributes to decrease the demand for cooling energy [4]. To prevent indoor overheating, passive and resilient design interventions may be integrated with the building design. In tropics, with the presence of high levels of diffuse radiation due to cloud cover all year around, the need to overcome indoor overheating is significantly important in lowering the demand for cooling energy and as a prerequisite for passive cooling in lowering indoor air temperature levels than the corresponding ambient levels.

On the other hand, addressing environmental heat stress on air conditioned buildings is an essential phenomenon to study. In such conditioned buildings, environmental heat stress through façades to 
indoors may not be visible and sensible to the occupants but contribute to increase the energy use in air conditioning, exacerbating the emissions and warming problem [5]. Thus, in-depth understanding of pattern of heat stress on air-conditioned buildings becomes imperative and performance improvements of these buildings in tropics are yet to be achieved. There is lack of consensus surrounding measurement and reporting of heat stress in buildings in tropics. Specific aim of this paper is to develop an empirically tested prediction method to ascertain environmental heat stress pattern on façades and thus indoors of three building typologies i.e., shallow, deep and closed atrium. Research questions the plan depths of these building typologies in relation to heat stress on façades and distribution of indoor air temperature pattern across spaces. This will enable the understanding of plan depth-specific factors of indoor overheating patterns. Objectives of the work were to quantify the extent to which heat stress occurs in these buildings and to analyze indoor air temperature distribution across plan depths with a focus on learning the significance of plan form depth on indoor air temperature distribution. The work used a comprehensive field investigation on thermal behavior of selected multi-level office buildings in Colombo.

\section{Background, State-of-the-Art}

Addressing indoor overheating risks in buildings in cooling-dominated climates has been seen as a growing research interest even under current climate scenarios. This has been further driven by current climate change projections and unintended consequences of poorly integrated interventions in building design as well. Review of literature, presented below, reflects a mapping of overheating risks due to environmental heat stress and identification of state-of-the-art prioritization areas in order to address these risks in office buildings in both free floating and air-conditioned modes.

\subsection{Indoor Overheating and Energy Use}

Peer reviewed data on climate change based on main sources such as the Synthesis Report of Intergovernmental Panel on Climate Change [6], suggests an increase of GHG emissions and annual temperatures over the years. IPCC's Synthesis Report shows that increase of GHG emissions would result in further warming in the global climate system [6]. Warming climates could directly enhance indoor overheating potential in buildings [7]. Previous studies have shown strong evidence to justify that increase of average external air temperature and indoor overheating could considerably increase cooling load [6,8-10] and thus emissions.

Research evidence predicts more warm days in sub-tropics and tropics thus limiting the efforts of emissions reduction strategies in building sector. Computer simulations have predicted that contemporary office buildings that are designed in current sub-tropical climatic conditions are subjected to the risk of further overheating with increasing warming weather [10]. Hence the need to understand the thermal behavior patterns of buildings is vital if design strategies need to be integrated more meaningfully to address indoor overheating.

Climate data from Department of Meteorology, Sri Lanka, indicates an increase of monthly mean temperatures over the past decades (Figure 1). Nevertheless, in recent years, new design styles with more glass façades are being added to the building population in Sri Lanka purely on aesthetic purpose and environmental and climatic dimensions are in question. These contemporary buildings add new corporate images for respective client organizations and enhance class one material comfort for the occupants but serious concerns over the thermal and energy performance remain significant.

In such a context, an examination of existing buildings in relation to the global problem of warming and prevailing building practice could easily be useful in quantifying the problem and, then to suggest appropriate solutions in future practices. Further, the research aims at highlighting why heat gain risks in tropics is severe and building-climate interplay is in need of a new direction. 


\section{Monthly average of April Maximum}

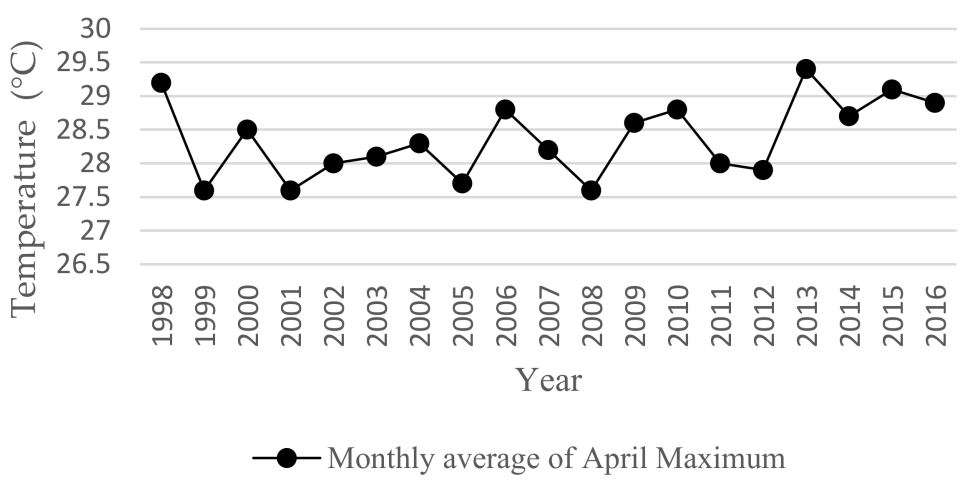

Figure 1. Mean monthly air temperature (for example March) since 1998 in Colombo is slightly on the increasing side (Data source Met Department, Colombo).

\subsection{Interplay of Building and Climate in the Tropical Context}

Climate is a catalyst that affects building-climate interplay and thus indoor climate in the operational stage of a building and thus need for energy. Microclimate around the building, plan depth and sectional profile of the building form, thermo physical characteristics and design of the building envelope are significant areas that need to be addressed though interventions.

Indoor thermal load profiles in buildings due to internal or environmental heat stress regulate the internal air temperatures of buildings and thus energy use [11]. This profile can either be of internal load dominant or environmental load dominant due to a diversity of heat gain sources.

In warm humid tropical climates, environmental loads play a major role in the problem of making naturally ventilated buildings overheated. The risk of heat stress on the façade of a building makes the process of maintaining the average indoor air temperature close to the required comfort zone more challenging. Due to the complexities of climatic interactions, the building components may tend to play a dual role in climate response. The best example is the building envelop, which can promote day light and ventilation but brings heat into the building indoor environment the same time in addition to the conduction heat gain. Hence, in building-climate interplay, addressing contradicting behaviors like this within a holistic manner becomes vital.

Several interventions in buildings, to promote indoor comfort and reduce the energy consumption for cooling have been investigated and assessed [12]. Givoni [13] highlights that in warm climates, natural ventilation is desirable when the outdoor air is at a lower temperature than the indoor air or when it can prevent indoor overheating caused by direct or indirect solar gain. A pioneering work on thermal mass [14] showed that indoor air temperature in a building with closed windows during day and night ventilation can be stabilized despite outdoor peaks.

Similar experiment method was found applied to a study in Galle, Sri Lanka by Rajapaksha U et al. [15]. This experimental work on the site showed how building envelope with high thermal mass and night ventilation contributed to reduce indoor air temperature during the day by $2.5-4^{\circ} \mathrm{C}$ lower than the ambient. Potential of thermal mass for passive cooling was seen with the support of diurnal range between 7-8 degrees $C$ for warm humid climates. A previous study of Rajapaksha I, [16] had justified the same potential of thermal mass. The evidence of these researches can be used to justify the efficacy of building-climate interplay for indoor thermal comfort. However, day time ventilation has a relatively small effect on the indoor air temperature of buildings protected from solar radiation and its main function is to directly enhance the comfort of occupants [13].

\subsection{Limitations of Airflow in Tropics}

The textbook on Introduction to Architectural Science by Szykolay [3] discusses in detail how the physics of heat flow behave with building components and elements of climate in affecting indoor 
thermal environments of buildings. Ventilation helps to improve thermal comfort, indoor air quality and remove toxic mold grow in buildings [17] but has limitations. Research evidence challenges the linear function of the cooling effect of air velocity. Accordingly, cooling effect of air flow works up to a certain limit and the effect diminishes with elevated velocities after $1 \mathrm{~m} / \mathrm{s}$ [18].

Work of Szokoloy [19] illustrates that indoor air movement at $1 \mathrm{~m} / \mathrm{s}$ can extend the upper limit of comfort zone, $28^{\circ} \mathrm{C}$, up to $31.7^{\circ} \mathrm{C}$ in warm humid climates. Further, an air velocity of $1.5 \mathrm{~m} / \mathrm{s}$ can extend the comfort zone by 5 degrees $\mathrm{K}$ up to $33^{\circ} \mathrm{C}$. An air velocity higher than this speed could cause thermal discomfort. However, it is a known fact that day time dry bulb temperature in these climates (Colombo for example) moves around $34^{\circ} \mathrm{C}$ or higher on a typical summer day. Therefore, it is quite difficult to experience thermal comfort given the daytime relative humidity levels around 80 percent and the limitation of the air velocity up to $1 \mathrm{~m} / \mathrm{s}$, in addition to internal loads from occupants and heat stress from outside. Therefore, there is a need for lowering the daytime indoor air temperature below the corresponding ambient levels in free floating conditions.

\subsection{Multi-Level Air-Conditioned Buildings}

Façade area of a multi-level building is greater as compared to a low rise building and plays a significant role in the building-climate interplay. A more climate responsive façade is able to control environmental heat gain and access for daylight and ventilation without heat gain [14]. Even if the building is air-conditioned, control of environmental heat gain through the envelope remains a requirement. The ideal façade architecture in air-conditioned buildings integrates interventions of U-Value technologies [11] which are able to control the elevation of indoor air temperature above the ambient levels through insulation, both resistive and capacitive, [3] and solar shading to avoid heat transfer from outside and thus maximum opportunity for adaptation to outside hot climate and reduce cooling energy loads.

An experimental study on design priorities to restrict dynamics of external heat loads with an average ratio of glazing to façade area around 43 percent, external sun shading devices, insulation, solar control glass and to remove internal heat loads with night ventilation and slab cooling has shown that the primary energy use of office buildings can be reduced to about one-third of the average building stock and kept within a limit of $100 \mathrm{KW}$ h per net floor area per year for moderate climates. This includes energy for heating, ventilation, cooling and lighting as well as auxiliary energy and energy dissipation by conversion from primary energy to end energy [19]. Lam's [20] study using a DOE (Department of Energy) simulation based on a generic model of common characteristics of 146 existing high rise commercial buildings in sub-tropical climates suggests that envelope as a major design aspect that affects building cooling load and air conditioning as the single largest electricity end user.

Shading has extensively been used for protection against solar heat gain from outside. The entertainment of a shaded air layer inside a double skin façade using a shutter with a heat resistant of $1.0 \mathrm{~m}^{2} \mathrm{~K} / \mathrm{W}$ can give a potential reduction of heat transmission of about 50 percent when compared to the standard choice of a 2-layer low energy glazing, meaning reducing heat development outside the glazing areas can reduce heat gain risks [21]. Similar studies are indicated by others for naturally ventilated environments highlighting the cavity space and the height of the double skin façades are crucial design factors for buoyancy effect of airflow [22] and more studies are available for air-conditioned environments as well. Decrease of solar insolation on façades in sub-tropics and increase of energy saving (while balancing day light and visibility) are linked to self-shading of façades due to orientation, azimuth angles and locations of buildings [23]. High reflectance on the surface finish of the outer façade can lower the heat transfer and thus indoor air temperature and cooling loads significantly [24].

Studies on heat gain risks and required solutions for tropics are least available and most studies available on cooling and façades of office buildings are on free floating conditions and use software simulations as the primary tool of research method [25]. Knowledge gap visible is the need for performance driven on site field investigations on architectural integration in real buildings, specially 
taking air-conditioned buildings and heat gain risks on them. Removal of internal heat gain from occupancy, lighting and equipment to a heat sink is another significant condition to be addressed. Halawa et al. [26], reviewing on energy conscious designs of building façades, argues that there is a research gap and a lack of a systematic and comprehensive analysis of the available literature regarding the energy and thermal performance of building façades based on the various possible design and technical configurations, especially in hot and humid climates. A recent research to quantitatively analyze the impacts of building envelope design factors upon cooling and heating loads in US cities of different climate zones suggests the importance of having variations in optimal sets of design factors in different climate zones [27].

A review of the effect of building envelops of high-rise buildings in hot-humid climate on the thermal comfort and energy efficiency focusing the Malaysian tropical climate highlights passive design method as one of the most potential strategies applied on building envelope in hot-humid tropical regions and based on the research findings in the same context establishes recommendations for envelop design strategies to be used by the designers for high-rise buildings [28]. Similarly, a number of researches have been carried out worldwide that indicate the importance of the building façade design on thermal performance of a particular building and on energy efficiency [29-32].

The growing trend of modern glass façades buildings in tropical Sri Lankan context signifies the urge of establishing a framework for building design applications along with climate responsive interventions. The common practice in the existing context is based on the aesthetical appearance where no concern to overcome barriers of overheating and high energy demand is given. On the other-hand, the research evidence on such aspects are lacking thus the need for conducting investigations to identify the barriers and opportunities related to building designs and thermal performance is highly required.

\subsection{Reducing Heat Stress-An Insight into Theoretical Aspects}

Studies indicate that overheating risk due to heat gain in buildings is already a problem in many building types across warm climates around the world. The literature offers a range of long term monitoring and simulation studies on overheating aspect of buildings with free floating conditions. Overheating due to heat gain by conduction through the outer façades and accumulation of internal loads has been discussed. Establishment of level of indoor overheating and the criteria to assess this are typically developed based on expectations of the occupants. Acceptable indoor air temperature levels for occupants are established using adaptive method [33] and acknowledged in international standards [34]. These recent comfort theories have acknowledged the interaction between people and their surrounding environment. It suggests that people who live in warmer climates can tolerate higher levels of air temperatures than the people who live in colder or moderate climates. It also points out that danger of overheating can be assessed in these buildings in which a relationship between the indoor comfort temperatures is derived from the mean of outdoor air temperature [35]. The range of acceptable indoor air temperature can be wider for occupants in both residential and non-domestic buildings with free running spaces where cooling is achieved by behavioral changes or options for user controlled ventilation strategies. The proportion of occupied hours with temperatures above an extended threshold gives an indication about overheating [36]. Overheating criteria has extensively been defined for residential buildings based on comfort expectations of occupants in many European climates and warm humid climates as well. Overheating is found to occur in vulnerable homes in European homes with poor ventilation even in the absence of heat waves [37] attributing to the poor air quality and occupancy behavior.

Overheating potential of buildings cannot be visible in conditioned buildings due to air temperature control by active means inside and little is known about heat gain stress on air conditioned environments/buildings in severe tropics. Addressing heat gain risks would allow a more climate sensitive façade design performance and would lead to avoid heat stress on façades. A current limitation with understanding environmental heat gain is that the complexity of defining the full impact of varied types of surroundings on the building. This is at least partially a result of the 
behavior of anthropogenic heat from traffic, albedos and geometries of urban canyons, climate type and orientation of the built mass to solar and wind access. This behavior is interconnected and becomes more complex with the dependency on a variety of design factors of the building concerned as well. Further overcrowding which leads to smaller building plot sizes results in diminishing the ability to cool buildings due to the thermal interference of neighboring structures [38]. However, there is currently no simple matrix for quantifying integrated heat risks on buildings in tropics and further the performance of building façade cannot be looked in isolation. Thus, the body of research knowledge on façades and the knowledge on the bioclimatic approach to building-climate interplay need to be brought together.

Bioclimatic design [39] approach is seen as an appropriate basis, which involves a way buildings filter and modify the external climate for occupants' comfort, to deal with energy efficiency opportunities. The need to have bioclimatic design in practice has been discussed as a good human adaptation of free running buildings in warming climates [40,41]. Bioclimatic influence can be effective in the manipulation of environmental loads and internal loads as well. This is easily applicable in skin dependent inclusive modes [42] of buildings because of the potential interaction between climate, building design and occupants. The involvement of building design between climate and occupants for thermal comfort in tropics is based on the integration of the microclimate enhancement, form and envelope of the building [15].

Microclimatic enhancement can be effective in air-conditioned and mixed mode buildings as well. Microclimate enhancement and calibrating the form and envelope design can be considered as effective input measures to reduce heat gain risks of externalities such as climate on the building (and its façade). Manipulating form (both plan and sectional) and envelope can remove internal heat gain from the building interior through buoyancy effect of sectional form and heat sink effect of thermal mass and air. For this, night ventilation is beneficial and tropics are now beginning to appear with diurnal ranges around 6-8 degrees C. Microclimate around a single building is diverse. Research has indicated that different microclimatic effects with regards to air temperature, solar radiation, shading and wind effects can occur around a single building [43]. This non-uniformity can be attributed to the building's plan form, sectional form, its orientation and design components of the microclimate.

Benefit of climatically linking inside and immediate outside of a building with substantial shading has been highlighted for indoor comfort improvements [38]. The research evidences suggest manipulation of plan form, sectional form and orientation can create shading on the external building façades against direct solar access creating shaded building microclimates that would be central to reduce heat transfer through the façade. If the building is ventilated in the night, substantial removal of internal heat and improving heat sink effect of the envelope for the following day is possible based on the buoyancy effect attributable for the sectional form and plan form [15]. Similar work is indicated by others for warm humid climates $[44,45]$.

Manipulation of building geometries for night ventilation is applicable for air conditioned buildings as well suggesting differentiation of thermal performance standards-a new thinking towards mixed mode buildings in the tropics with night ventilation. A critical need is to work out a sensor technology and time management frame to open the stack flow in the night and early morning hours. More research is required in this respect.

A simulation study carried out to identify the performance of different building façades in moderating the indoor temperatures of building interiors and to reduce the external gains established evidence that glass façades in tropical Sri Lankan context influence external gains while increasing cooling load requirement. Onsite investigations conducted in sequence to the same study signified that provision of night ventilation reduces the indoor air temperature of the built spaces the following day [46]. In contrary to this practical scenario the trend is heading to glass façades as stated earlier thus indicating the knowledge gap of building designers and their less concern.

A recent study [47] conducted in Colombo context to identify temperature behavior around building façades in different levels of multi-story buildings implies that the temperature behavior 
around the façades differ in each side of the building as well as in different floor levels of the building. The findings suggest that the building façade, rather than being monotonous, should be designed considering the orientation of each façade as well as the vertical micro-climatic diversity. As a result of the investigation, it was visible depending on the building plan form the thermal behavior differentiated. However, this is an area to be further investigated in practical applications.

Nevertheless, in tropical Sri Lankan context though theories related to building forms and the thermal performance is adapted in few practices, the practical situation and the actual performance of such theoretical interventions are not investigated in relation to the climatic context of Sri Lanka. This is identified as a research gap to be investigated. With the aim of fulfilling this objective the research attempts to compare at real scale thermal performance of three distinct plan depth types with similar building heights and façade characteristics. Sampling of 86 plan forms available in Colombo Metropolitan Region (CMR) contributed to identify three main plan depths; shallow, deep and covered atrium types.

\section{Research Methodology}

The paper develops an evidence based narrative for different plan form typologies using on-site thermal performance investigations in quantifying the heat gain risks on them and discussing means of reducing that on air-conditioned buildings. The initial phase of the study was conducted involving 86 multi-level office buildings in CMR. These buildings with multi-level floors ranging from 4 to 14 are being used for office, bank and other commercial functions. The buildings are located in very dense urban areas on small plot of lands ranging from 100 to 3000 square meters. Building Energy Index (BEI) was calculated for all 86 buildings in order to identify the building population in respect to energy usage and efficiency levels. BEI was simply calculated by dividing the total annual energy usage by the total usable floor area of each building. Annual BEI of these office buildings was found to be within a range from $90-412 \mathrm{kWh} / \mathrm{m}^{2} /$ a. Majority of these buildings are found to be with BEIs higher than $110 \mathrm{kWh} / \mathrm{m}^{2} / \mathrm{a}$, which is an acceptable standard for the energy efficiency building codes [48]. Further, the mean BEI for building stock in CMR is $212 \mathrm{kWh} / \mathrm{m}^{2} / \mathrm{a}$ and thus solidifies that the office building stock in CMR is energy obsolete [49]. Regrettably, the typical office building stock in CMR is not designed with an explicit intent to include climate and environmentally responsive design considerations.

The next phase of the study selected 12 free standing office buildings (from the larger stock of 86) primarily having distinct plan shapes. This phase categorized the office building stock of 86 into 12 buildings with significant six types within generalized basic plan forms and composite plan forms. Both the basic plan forms and composite plan forms consist of shallow and deep in addition to a courtyard (atrium) form. The selected twelve buildings included an atrium form having a glass roof on top making the atrium space at the ground level a tall internal lobby space-a common practice with most compact urban atrium buildings in Sri Lanka. Since the atrium is covered at the top level with a glass roof, the enclosed space inside the atrium does not experience any air moment due to stack flow except the air coming from the side corridors and entry points to the atrium in different heights. The purpose of having an atrium for vertical air moment is completely lost in these buildings due to the glass roof cover at the top. This research intended to highlight this drawback with performance evidence.

Façades of these 12 sample buildings are composed of glass windows, brick walls and aluminum cladding. Percentage distribution of these materials in front façades is approximately $30-57 \%$ compared to the other façades. Glazed façades are primarily fixed with glass panels with very few operable windows. Glazed façades are orientated to varied directions with no concern to control unwanted direct solar. Building forms have almost similar envelope properties of cement plastered high mass concrete and brick without any insulation to control conductive heat flow from outside. Floor to floor height varies between 3 to $3.5 \mathrm{~m}$ in all these buildings, a common practice.

All 12 buildings are located in close proximity in Colombo City. Table 1 depicts the identified classification of 12 buildings and demonstrates their orientations and BEIs with envelope characteristics and plan typologies. Building morphology and performance data were focused on orientation, plan 
shape (form), construction materials and fenestration characteristics such as window to wall ratio (WWR), aspect ratio (façade length/depth). Monitored technical and operational characteristics included capacity of air-conditioning systems, operational work hours and types and usage of equipment. Occupied hours, occupancy profiles, air-conditioning systems and equipment characteristics were found to be nearly similar across this 12 building population but a clear difference was seen in respect to their BEI which was ranging from 106-400 $\mathrm{kWh} / \mathrm{m}^{2} / \mathrm{a}$. Of them three buildings with distinct plan forms are found to be with relatively lower BEIs but reason for that was due to their lower usage of air conditioning in occupied spaces. These three buildings accommodate some spaces with free floating conditions as well.

Table 1. A classification of the selected 12 plan forms of office buildings from a larger population of 86 buildings in Colombo. Most forms are composite shallow or deep plans, some are with atriums.

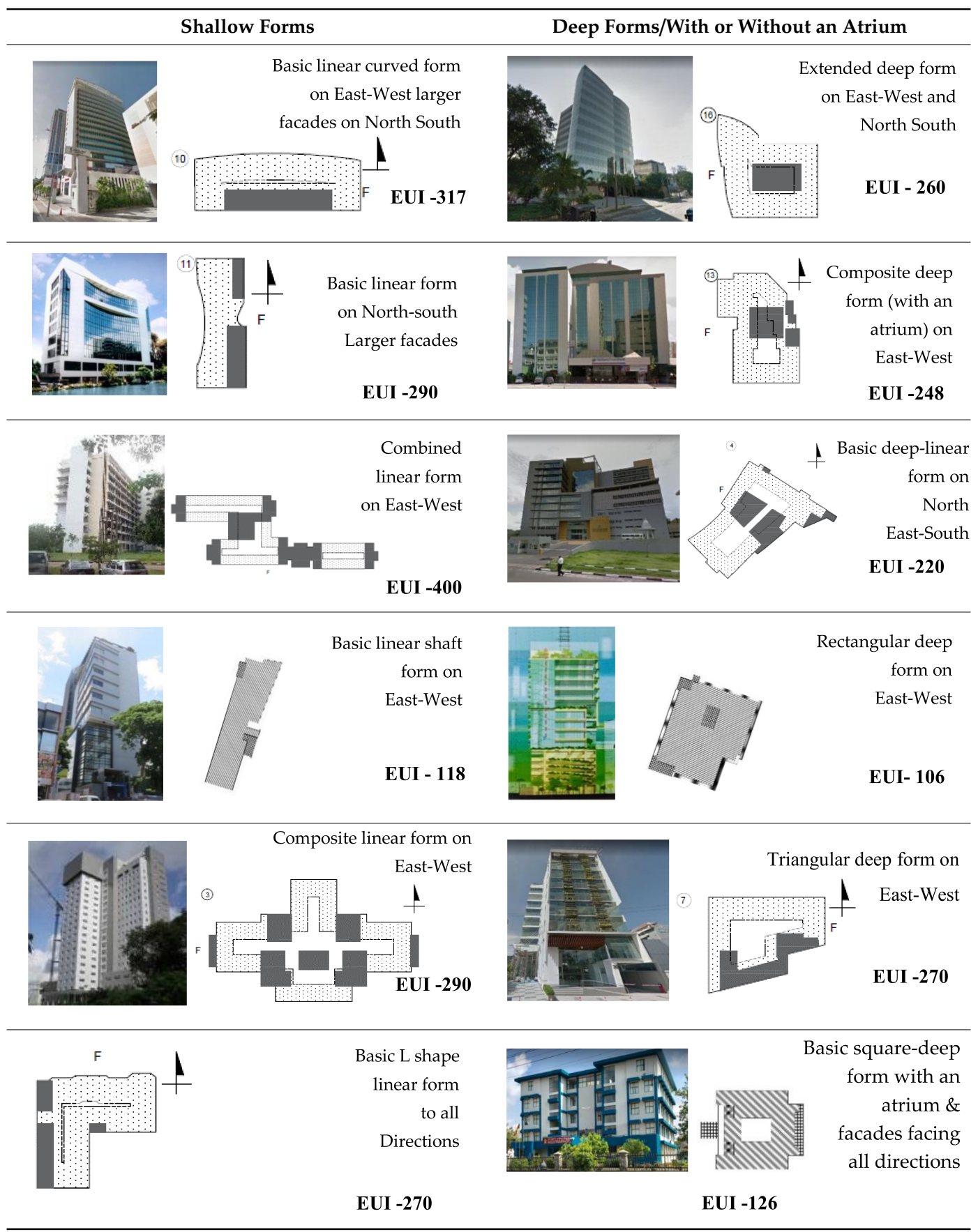


The work measured the levels of elevation of indoor air temperature as compared to the corresponding ambient levels as an indicator of heat stress on indoors. Similar methods have been used by others for research on residential buildings [50]. The buildings were investigated in weekdays during air-conditioned hours and weekends during non-air-conditioned hours as well making the visibility of heat gain risk easier. Free standing buildings provided an opportunity to measure the effects of surrounding climate with no thermal effect from other built structures closer to them.

Figure 2 presents decrement factor-the level of elevation or decrease of indoor air from the corresponding ambient air temperature-for the sample of selected 12 office buildings when air-conditioners are in off-mode in weekends. To obtain an idea about approximate heat stress on buildings, the decrement factor is used as an indicator. The majority of buildings' elevation of indoor air in the peripheral and central zones was remarkably higher than the corresponding ambient levels during AC off-mode with sealed windows, thereby indicating a greater potential for heat stress and indoor overheating in buildings designed for air-conditioned mode. Use of a multi zone method involved an investigation of air temperature behavior in peripheral and central zones giving more accurate picture about temperature distribution across an indoor space than taking a single zone investigation. Readings in four orientations in a peripheral zone were taken individually and averaged to one reference value. Similarly, three readings were taken in center zones of each building.

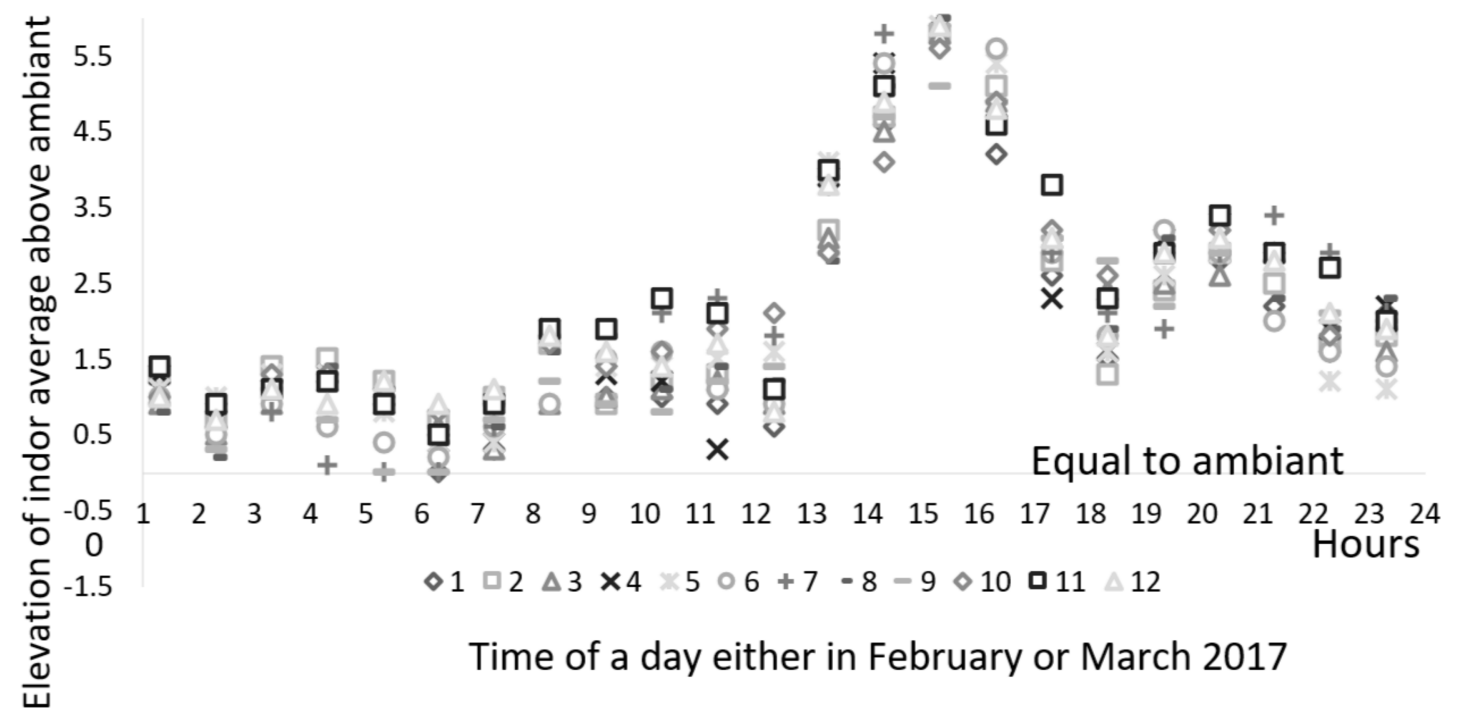

Figure 2. Elevation of indoor air temperature average well above ambient levels in 12 typical building indoors shows environmental heat stress on façades/envelopes.

Buildings are designed to run with conditioned environments and found to be in exclusive mode [42]. The U-value calculations of each case is worked out following the standard equations using the general resistance values of typical construction materials used in Sri Lankan context. It is a commonly accepted factor that in tropical Sri Lankan context the most appropriate building orientation is north-south, in order to avoid direct solar gain into building interiors. However, orientations of selected buildings are not proper, contributing to solar exposure during morning and evening hours. Nearly 95 percent of multi-story office buildings in Colombo are facing major roads without responding to the required orientation. Although the work presented involves the City of Colombo, methodology and performance evidence are relevant to any other tropical climates, building typology and usage. A detailed on-site thermal performance investigation was carried out for three selected building forms shown in Table 2. The three forms, which are in slightly composite and compact are shallow, deep and atrium plans, representing most of the physical characteristics of the larger population of office buildings in Colombo. These three buildings were selected due to their distinct plan form type. 
Table 2. Three basic plan form typologies (shallow, deep and covered atrium) selected from a larger population of 86 buildings for the thermal performance investigation.

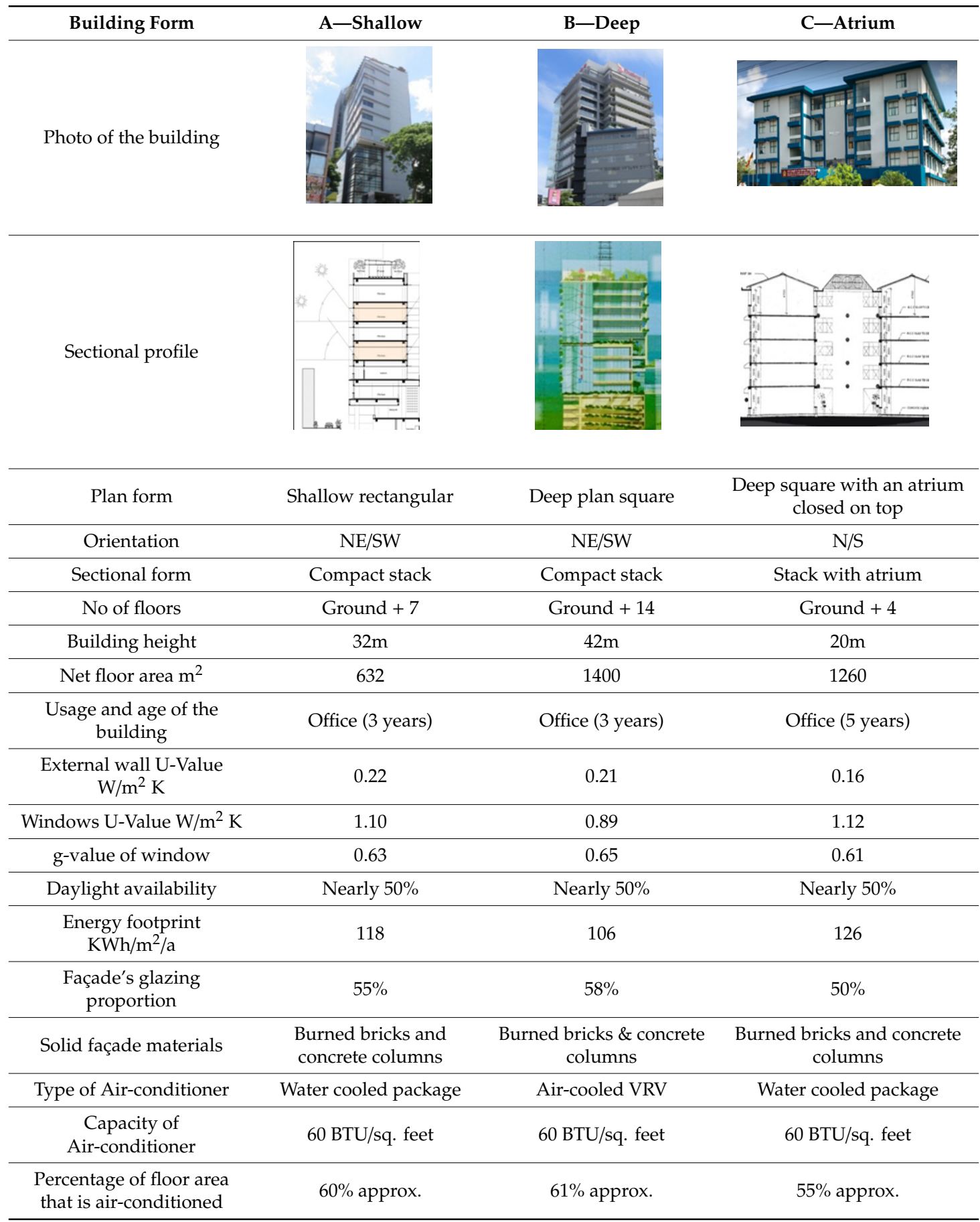

\subsection{Limitations}

The research aims at investigating the heat gain risk of multi-story air-conditioned buildings in tropical context. Air-conditioned office buildings were selected as the building category type for the on-site investigation. Further, Colombo, the existing commercial hub of Sri Lanka with a majority of office buildings and a typical tropical climatic context having an ambient temperature between $28^{\circ} \mathrm{C}-34{ }^{\circ} \mathrm{C}$ during a typical day was selected as the study context. Selected building population is designed with multi levels ranging from 4 to 11 floors in height. Nearly 60 percent of total building population in Colombo falls on to this category [51]. 


\subsection{Instrumentation}

Air temperature and wall surface temperatures were measured during April and May, 2016 and 2017, the hottest months of a typical year in these three selected buildings. Calibrated Hobo data loggers (Hobo for air temperature/RH and Hobo thermo couples with four external probe sensors each for surface temperature/RH) were used with temperature measuring range of -20 to +70 degrees $\mathrm{C}$ with accuracy $\pm 0.34 \mathrm{~K}$ and Relative Humidity range of $5-95 \%$ with accuracy $\pm 2.5 \mathrm{~K}$ of real scale readings. Data loggers and their sensors were shielded against solar and reflected radiation by placing them in a shade throughout the study.

\subsection{Rationale of Longitudinal and Vertical Thermal Measurements}

Multi zone temperature readings were taken over a weekend during air-conditioner off-mode and on Mondays with air-conditioner on-mode at $30 \mathrm{~s}$ intervals and later averaged to hourly values. Ambient hourly weather data was obtained from the Dept. of Meteorology, Colombo for specific dates, the on-site measurements were taken. The objective of the measurement rationale was to ascertain a number of comparisons as follows;

- Dynamics of air temperature distribution in peripheral and central zones in a typical office floor in order to look at combined effect of façades and plan depth on indoor climate in dealing with environmental heat stress

- Dynamics of indoor air temperature deviation against corresponding ambient levels in order to assess the heat stress from solar gains

- Elevation of indoor air temperature in peripheral and central zones across a typical floor above the set point temperature in air-conditioned mode

- Wall surface temperatures (both external and internal) with indoor air in order to assess heat stress from immediate building or urban microclimate on the façade and heat sink capacity of thermal mass and its impact on indoor climate

- Decrement delays of indoor air and internal wall surface temperatures inside three buildings for assessing any differences of plan form effect in addressing heat stress from outside

Since the atrium form is covered with a glass roof from the top, the atrium space was not monitored for its air flow behavior. It is important to note that monitoring air flow rates and patterns inside buildings was not a subject of the research in the context of buildings designed for air-conditioning. The use of criteria that define heat stress based on the elevation of indoor air temperature in respect to the set point temperature during air-conditioning and corresponding ambient levels during free floating conditions.

Monitoring air temperature distinction between occupied workspaces close to the perimeter façades and central zones away from the façades was expected to indicate the behavior and distribution of environmental heat stress across a façade through to the center of a typical floor plate. Similarly, air temperature distinction on the vertical path in the atrium building indicates the negative effect of glass roof of the atrium space.

\section{Results and Discussion}

Building A-compact shallow plan form

The typical office floor of shallow plan form (Building A) is shown in Figure 3. The building has a ground floor and 7 upper floors in compact and linear shallow plan form with longer façades facing northwest and southeast orientations. Nearly 80 percent of the total façade area is facing either direct or indirect solar access at least during 10:00 a.m. and 15:00 p.m.- - typical scenario of office buildings in Colombo. 5th and 8th floors were measured for thermal performance from Friday the 22nd April 2016 to Tuesday the 26th April 2016. Building Management System (BMS) indicated $24^{\circ} \mathrm{C}$ 
as the set point temperature of air-conditioned office floors on weekdays from 8:30 a.m. to 17:00 p.m. Air conditioner was on off-mode during the weekend.

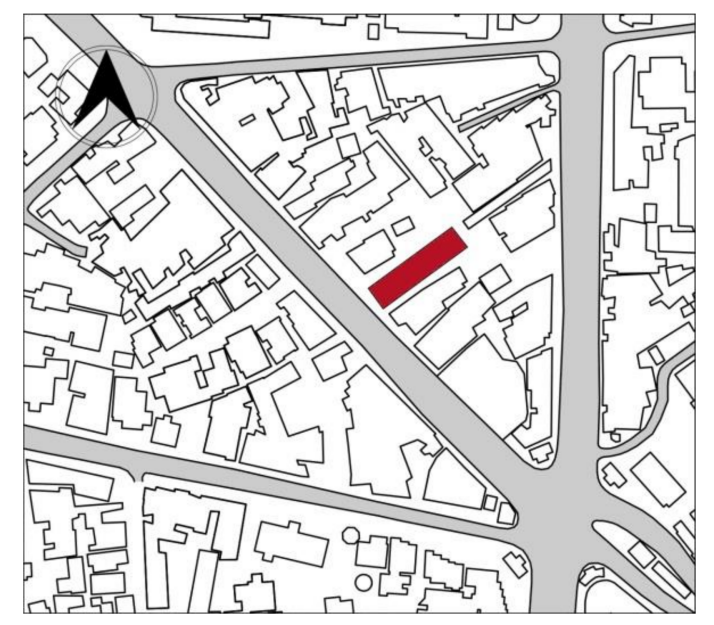

A typical office building with compact shallow plan with nearly $80 \%$ of facades areas facing direct or indirect solar access during midday

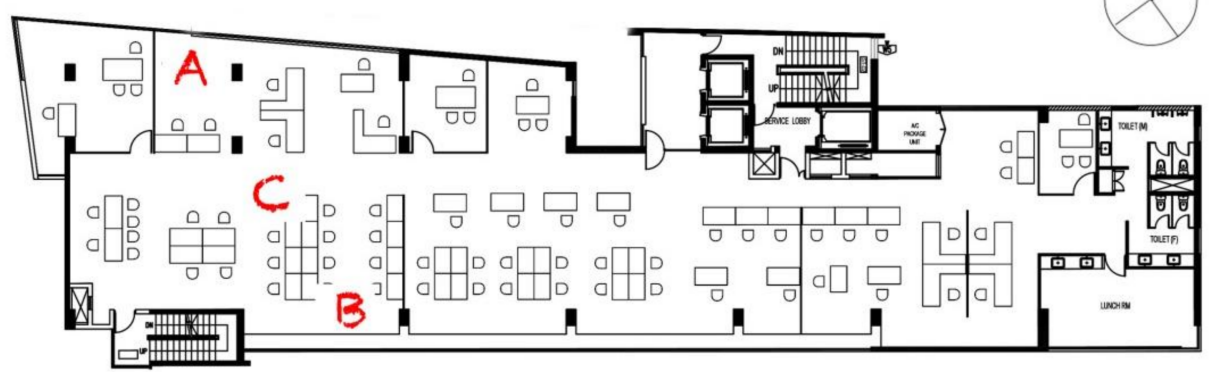

Figure 3. Building A (plan depth-14 $\mathrm{m}$, length—56 $\mathrm{m}$ ) shallow plan forms with unprotected façades contributes to heat stress from environmental loads.

Indoor air temperature in the peripheral zones A and B moved well above ambient levels during air-condition off-mode on Sunday the 24th April 2016 (Figure 4-Top). Peripheral zone on the southeast (Zone B) reached its maximum of $35^{\circ} \mathrm{C}$ by 8:30 a.m. and remained above ambient till 11:00 a.m. while the peripheral zone on the northwest orientation (Zone A) commenced its elevation above ambient by $11: 30$ a.m., reached its maximum, $42{ }^{\circ} \mathrm{C}$, by $14: 30$ p.m. and continued to remain higher than the ambient throughout the night. In the shallow plan form, the peripheral zone claims a larger occupied area and results indicate the severity of the heat gain risk due to environmental loads on façades. The central zone which is about $30 \%$ of the useable area and $5 \mathrm{~m}$ away from the periphery maintained its air temperature below the ambient but remained close to $29^{\circ} \mathrm{C}$ throughout the day. 

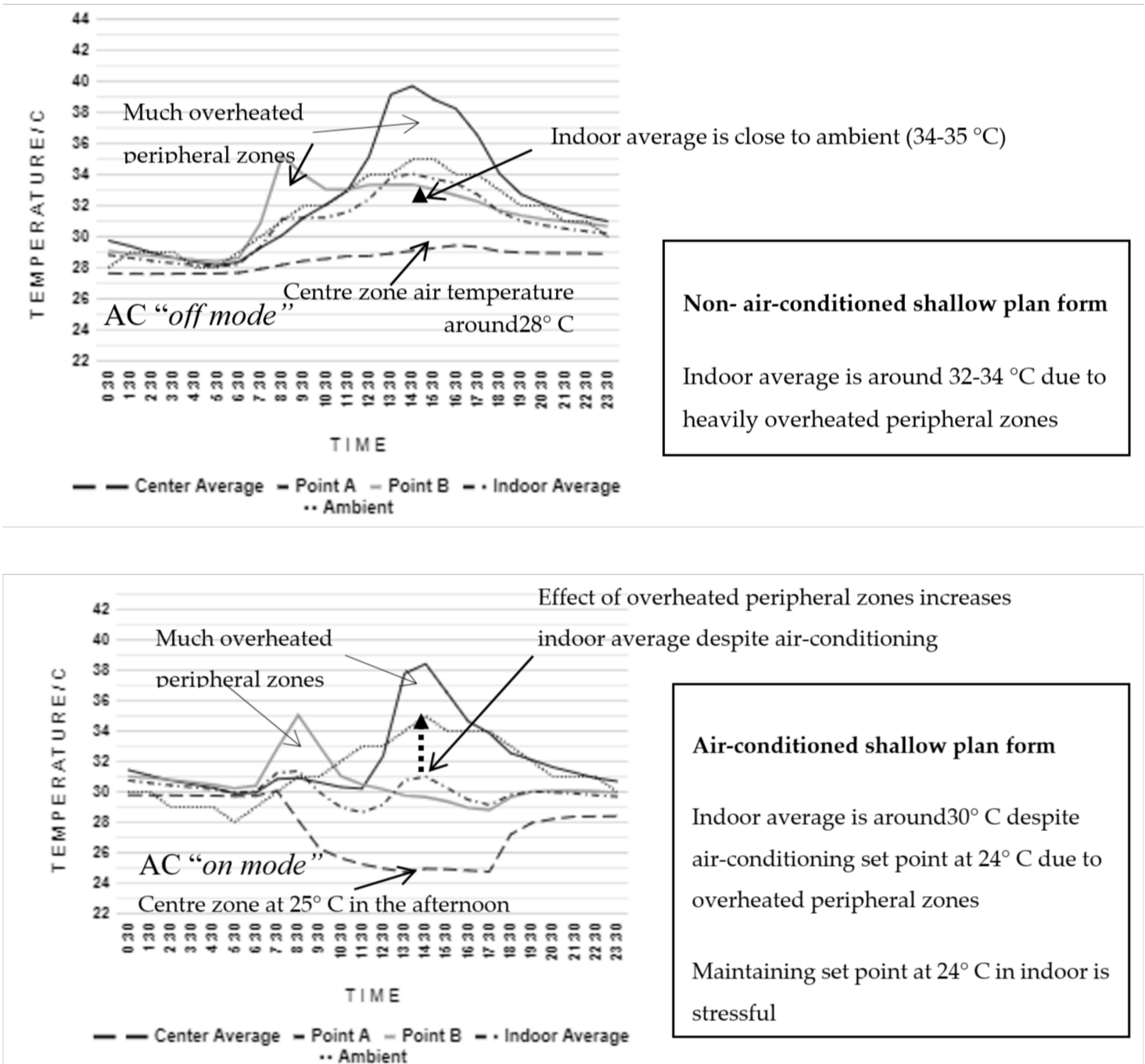

Figure 4. Air temperature inside 5th floor of Building A with shallow plan, Top-AC off-mode and Bottom-AC on-mode, overheated indoors due to environmental heat gain in both situations.

The distribution of occupancy, computers and other equipment were found to be uniform in both zones and investigation was carried out on a Sunday assuring that internal loads are not a contributing factor for this heat gain risk. The complete scenario highlights the severity of the office building population in Colombo and the need to protect the façades from environmental heat gain risks.

Indoor average of all zones closely followed the pattern of corresponding ambient levels but moved well above $33^{\circ} \mathrm{C}$ between 12:30 and 17:30 pm indicating heat gain risk on the indoor environment. Figure 4-Bottom shows the indoor thermal behavior of 5 th floor when the air conditioner is on on-mode on Monday, the 25th April 2016. Since the building is sealed and walls are insulated, indoor air temperature was recorded as $31^{\circ} \mathrm{C}$, which was about $3{ }^{\circ} \mathrm{C}$ higher than the ambient at $6 \mathrm{am}$. Despite set point temperature at $24^{\circ} \mathrm{C}$, starting at 8 am and during office hours, results indicated that indoor air temperatures in peripheral zones were extensively dynamic throughout the day in air conditioned mode reaching its peak to $35^{\circ} \mathrm{C}$ on southeast orientation at $8: 30$ followed by $38.5^{\circ} \mathrm{C}$ on the northwest orientations at 2:30 p.m. Internal air temperature at the center zone moved around $1{ }^{\circ} \mathrm{C}$ above the set point temperature and elevated to $28^{\circ} \mathrm{C}$ and above just after 17:30 when the air conditioner off, creating a more warmer environment in the night and heat stress on the air conditioner on the following day morning. Indoor average moved almost with the corresponding ambient around $34-35^{\circ} \mathrm{C}$ and showed the heat stress on the façade and its impact on the indoor average air temperature. 
Figure 5-Top explains the surface temperatures and heat stress risk on the external façade and its impact on the indoor wall surfaces in peripheral zone during AC off-mode. Wall surface temperature behaviors on the air conditioned mode day (25th April 2016) are shown in Figure 5-Bottom. Average of internal wall surfaces of the building façades (tiled floor not included) remained below the ambient around $30^{\circ} \mathrm{C}$ during air conditioned mode. Averages of all indoor air in the perimeter zone and outdoor air just outside the external façades were well above the ambient, reaching $38.3^{\circ} \mathrm{C}$ at $14: 30$ p.m. and $41^{\circ} \mathrm{C}$ at 15:30, respectively, a situation which cannot be expected in climate responsive design practice.
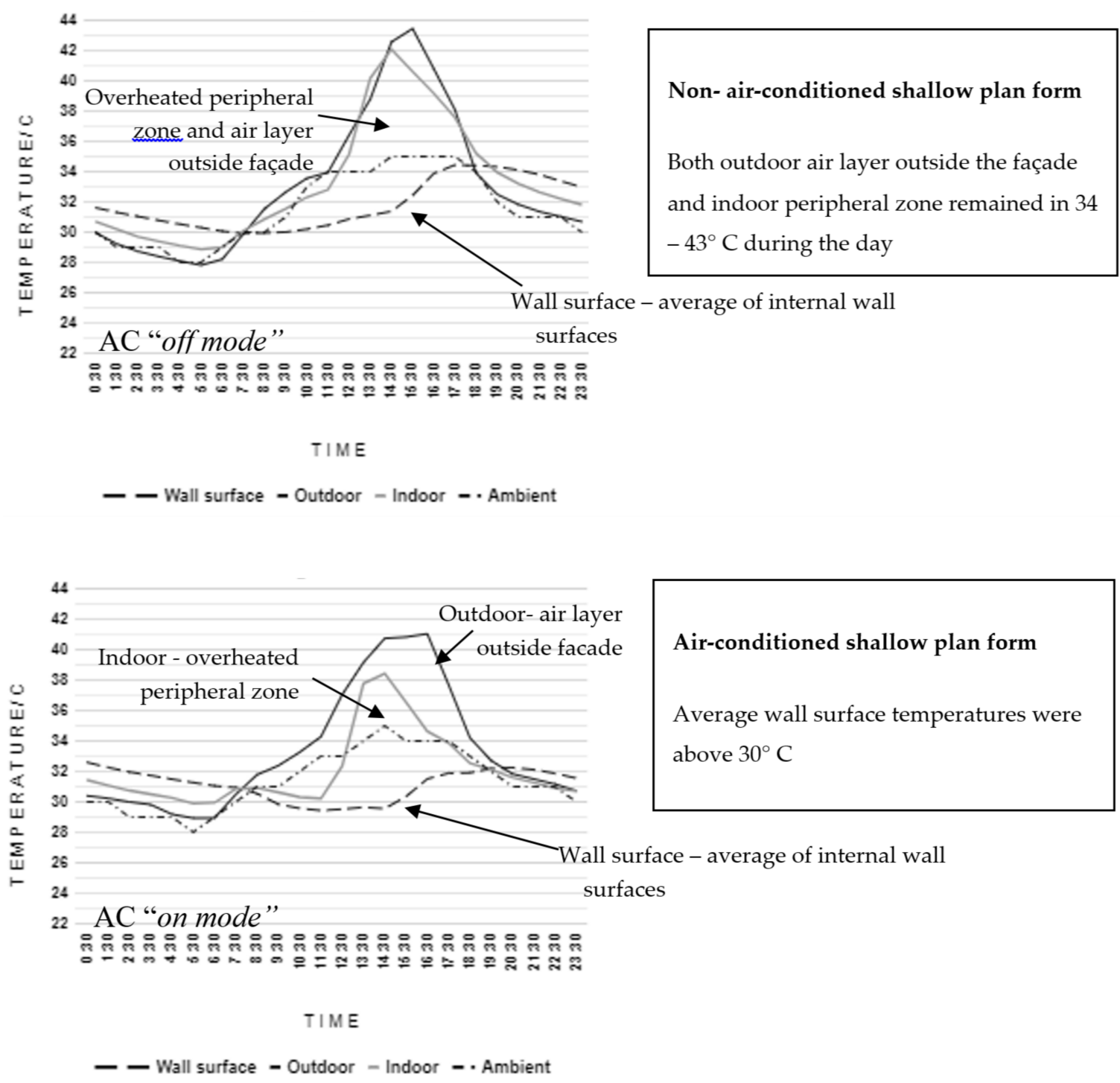

Figure 5. Indoor overheating in Building A with surface temperature behavior of façades and indoor peripheral zones moving around $40{ }^{\circ} \mathrm{C}$ in both AC off-mode (Top) AC on-mode (Bottom).

External air layer just outside the building façade moved around $34-44^{\circ} \mathrm{C}$ during daytime. During AC off-mode, average of indoor air in the periphery remained high as $32-42{ }^{\circ} \mathrm{C}$ during daytime. Comparison of Figures 4 and 5 shows that maximum of indoor air in peripheral zones has come down only by $3.5^{\circ} \mathrm{C}$ when the indoor environment was changed from AC off-mode to AC on-mode. Heat sink effect of internal surface of the façade was visible by moving its surface temperature $2-4{ }^{\circ} \mathrm{C}$ below the ambient and $2-10{ }^{\circ} \mathrm{C}$ below the indoor periphery but has been unable make any impact on indoor air in both AC on- and off-modes due to direct heat transfer through the façade. 
Building B-compact deep plan form

The Building B, with a deep plan form, is shown in Figure 6, and has a ground floor and 14 upper floors in compact form. Nearly $80 \%$ of the total façade area is facing either direct or indirect solar access during a typical day-a typical scenario of office buildings in Colombo. Parking facilities are given in the 2nd to 5th floors with natural light and ventilation. From 7th floor up to the 14th floor are allocated for typical office functions. Central zone in a typical floor is slightly larger than the peripheral zone which falls within $5 \mathrm{~m}$ from the external façade. The 7th and 12th office floors were investigated from Friday the 1st April 2016 to Tuesday the 5th April 2016. Results of 3rd Sunday (AC off-mode) and 4th Monday (AC on-mode) are presented here. Building Management System indicated $24^{\circ} \mathrm{C}$ as the set point temperature of air-conditioned office floors on weekdays from 8:00 a.m. to 17:00 p.m. Air conditioner was on off-mode during the weekend.
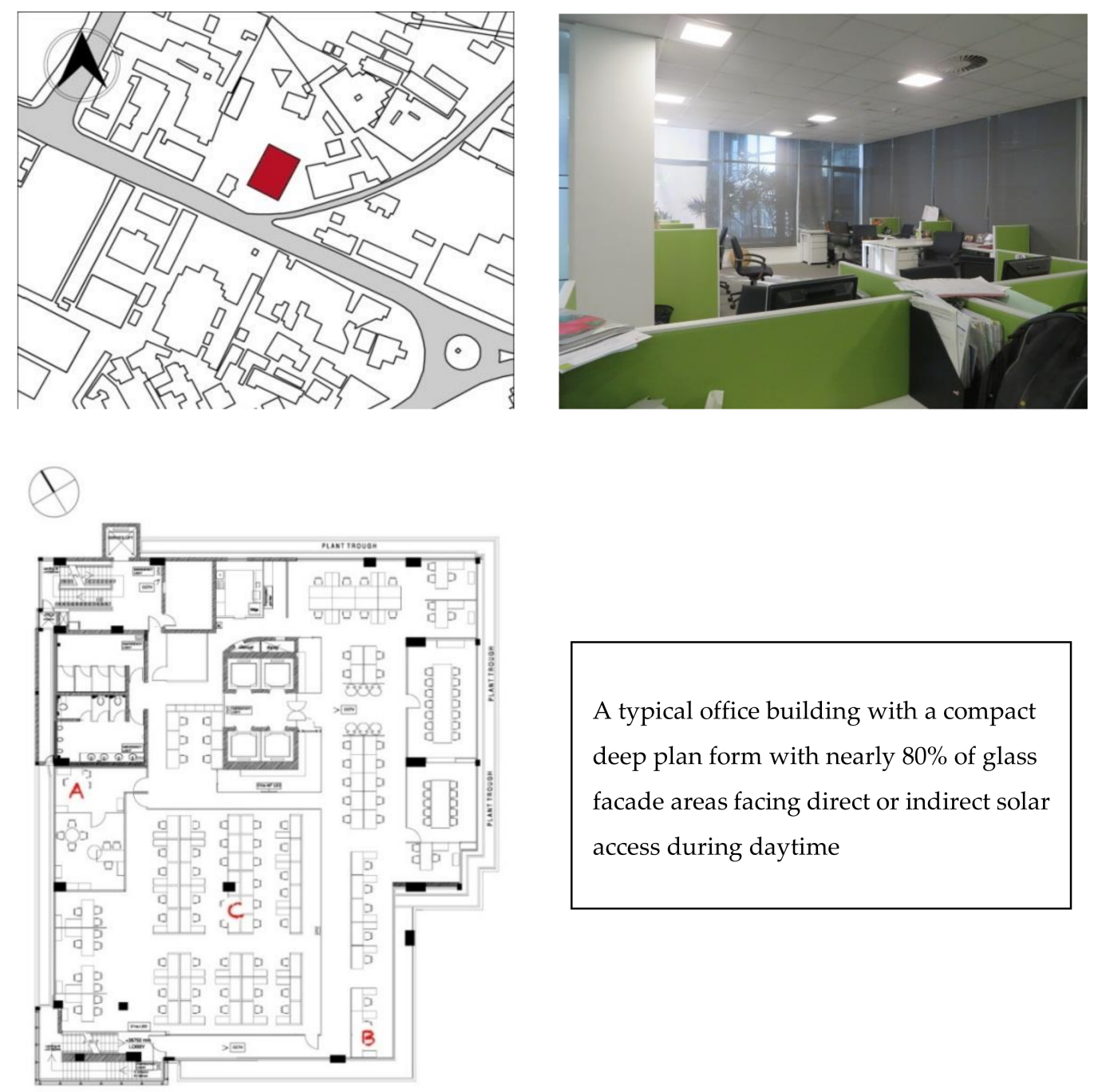

A typical office building with a compact deep plan form with nearly $80 \%$ of glass facade areas facing direct or indirect solar access during daytime

Figure 6. Deep square plan form of the Building B (plan depth-24 m, length-55 m) Top left-Layout in the urban setting, Images-internal office and equipment setting, Bottom-typical floor plate.

Figure 7-Top shows the thermal performance behavior of the 12th floor on Sunday the 3rd April 2016 when AC was on off-mode. Indoor air in the peripheral zones moved well above ambient in the morning and afternoon reaching its maximum of 42 at 9:30 a.m. and 37 at 16:30. This behavior is a result of heat stress on the façade and its poor performance. However, peripheral zones remained below the ambient during mid-day (10:30 a.m.-15:00 p.m.) due to shading created by overhangs on 
windows. Solar angles lower than $56^{\circ}$ in altitude results in direct solar radiation exposure on the westerly side with Window to Wall Ratio 0.4 (the easterly side employs larger windows WWR 0.6). Due to lower solar angle after $15.00 \mathrm{pm}$ on the westerly façades, peripheral zone on the west showed a sharp increase up to $37^{\circ} \mathrm{C}$ by $16: 30$ creating a risk on the internal zones in the night and following day morning (Figure 7-Top).

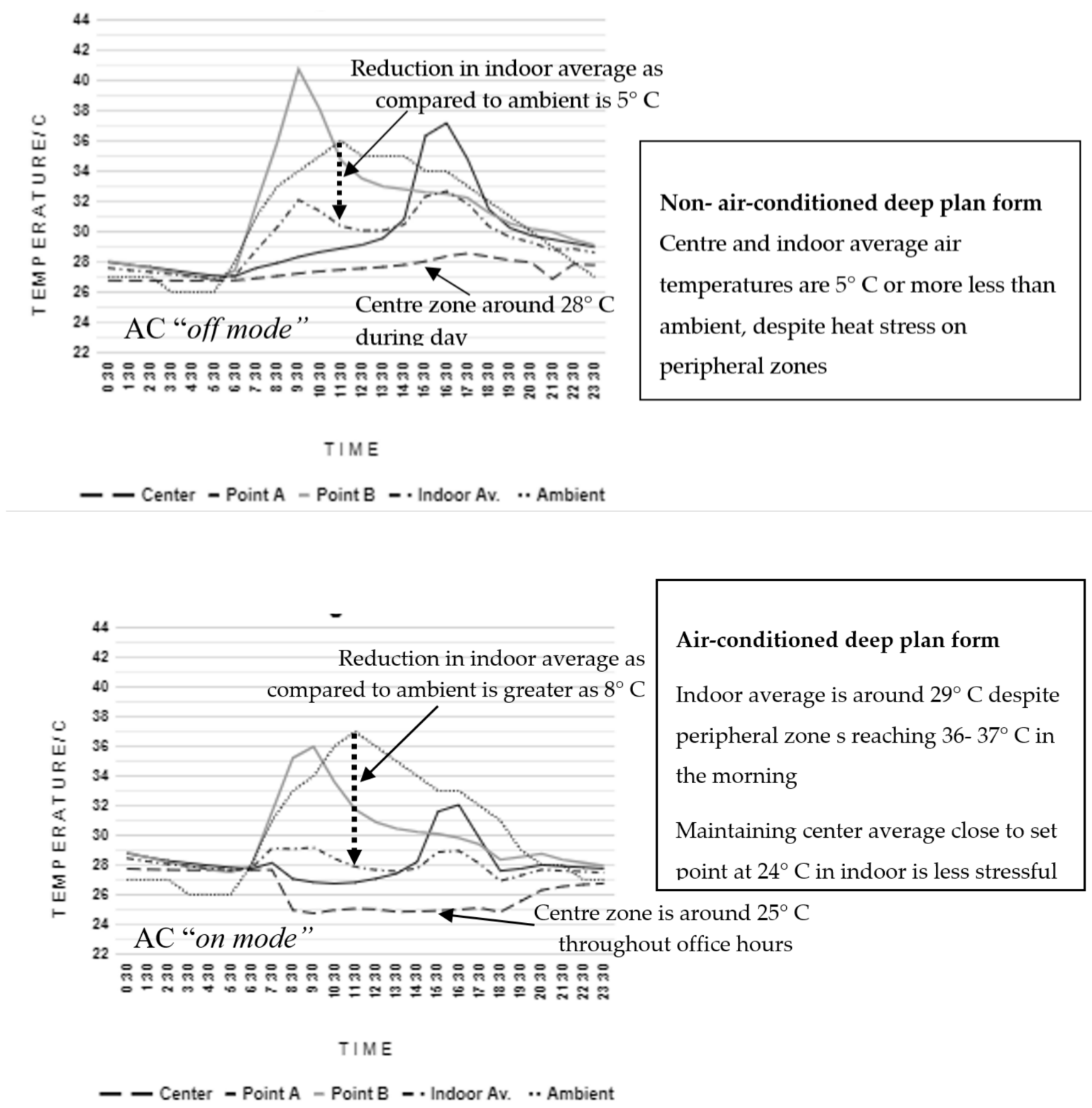

Figure 7. Top-12th floor of Building B in AC off-mode, Bottom-AC on-mode. Despite overheating in peripheral zones, center and average move closer to set point at $24{ }^{\circ} \mathrm{C}$.

Despite peripheral zones reaching extensively higher temperatures, the center zone maintained a consistent level around $28{ }^{\circ} \mathrm{C}$ in $\mathrm{AC}$ off-mode. Indoor average remained around $2{ }^{\circ} \mathrm{C}-5^{\circ} \mathrm{C}$ lower than the corresponding ambient. Results suggest that elevation of average air temperature in center is minimal in deep plan forms as compared to shallow plans.

Figure 7-Bottom shows thermal performance of the same floor (12th) when the AC was in on-mode during Monday the 4th April 2016. Despite set point at $24{ }^{\circ} \mathrm{C}$, the indoor average was in trouble and moved around $28{ }^{\circ} \mathrm{C}-29^{\circ} \mathrm{C}$ due to heat stress from the peripheral zone B just inside two southeasterly façades in the morning. However, center moved very close to set point temperature and as a result, 
indoor average was able to show some relief from the heat stress from peripheral zones during the noon. A reduction of $8^{\circ} \mathrm{C}$ from the ambient was clear in average temperature inside the spaces indicating an effect from greater percentage of center zones with lower temperatures close to the set point of $24^{\circ} \mathrm{C}$.

These initial results show just how much the monitored intensity and duration of elevated indoor temperatures in the building with a shallow plan form greater than the same in the building with a deep plan form. There remains work to be done on the impact of plan depth on the elevation and distribution of indoor temperature due to heat stress in overheating assessment but this research questions the contemporary climate responsiveness of shallow plan form which is considered to be an ideal solution for daylight and ventilation efficiency. More work involving a larger population of shallow and deep plan forms is yet to come in a future paper.

Figure 8-Top presents surface temperature of the building façades on the 12th floor on Sunday the 3rd April 2016 with off-mode of AC. Internal wall surface temperature followed the ambient pattern and moved around $29^{\circ} \mathrm{C}-30^{\circ} \mathrm{C}$ in the night and $30{ }^{\circ} \mathrm{C}-32^{\circ} \mathrm{C}$ during the daytime showing heat gain. Direct heat gain through windows was visible with indoor peripheral zone moving up to $40{ }^{\circ} \mathrm{C}$ by 9:30 a.m. and $37^{\circ} \mathrm{C}$ by 16:30 p.m. Thermal mass temperature moved higher than ambient in the night contributing to heat sink to indoor air. Heat sink effect of the internal surface was not visible at all in the absence of a method to remove heat from inside with night ventilation or any other means. Figure 8-Bottom shows that internal wall surface temperature during AC on-mode on Monday the 4th April 2016 remained constant around $29^{\circ} \mathrm{C}$ during both day and night. However, indoor air in the peripheral zones showed an increase up to $35.5^{\circ} \mathrm{C}$ with $\mathrm{AC}$ on-mode irrespective of constant level of internal surface temperature, This suggest lack of heat sink effect of internal wall surfaces but solar gain from the façades.

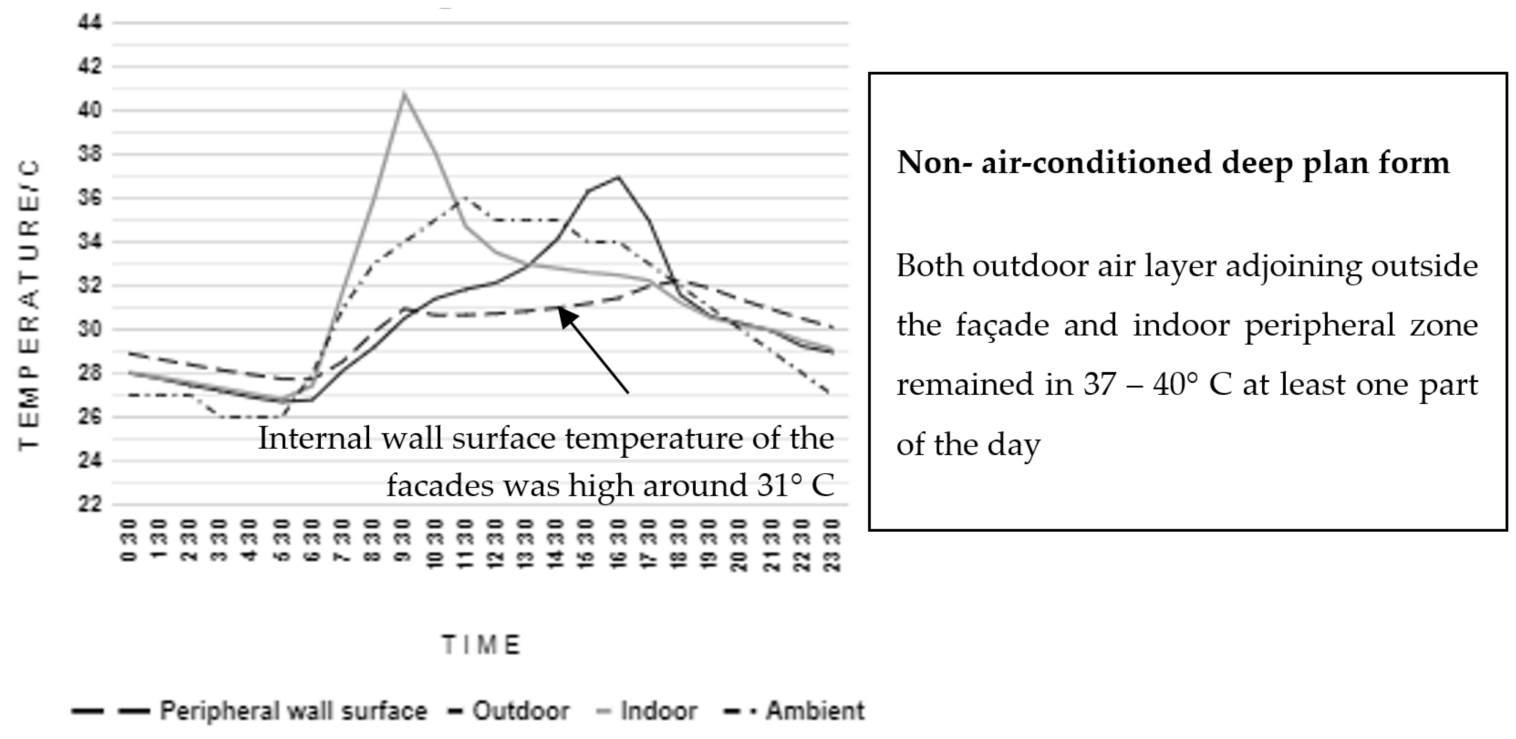

Figure 8. Cont. 


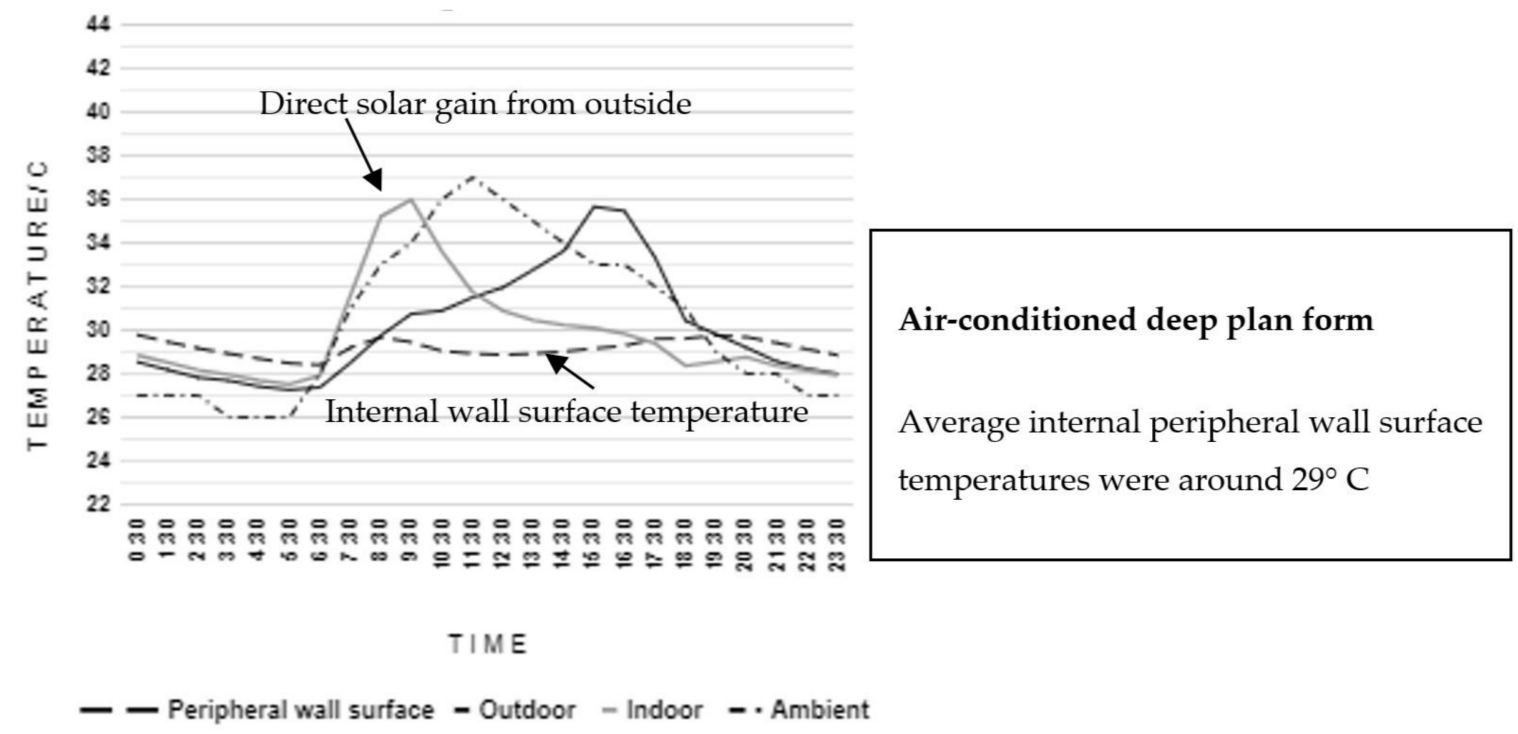

Figure 8. Thermal behavior of peripheral zones with wall surface temperature, Top-during AC off-mode and Bottom-during AC on-mode.

Building C-Atrium plan form covered from top

The building has a ground floor and four upper floors with an atrium (covered at the top) at the center in the deep plan form, which is another common form of practice in urban areas. The size of the atrium is $12 \mathrm{~m} \times 10 \mathrm{~m}$ and $15 \mathrm{~m}$ in height and is designed to enhance daylight but covered with a glaze roof top, which is in question (Figure 9).

The atrium is open at the ground floor level to outside through the main entrance, which is the only access point placed but on a wind shadow. Wind flow comes from the other side, southwest, of the building, Main office spaces on the east and west, which are air conditioned, have unprotected façades.

Air temperature measured on Thursday the 4th and Friday the 5th May, 2017 at $1.5 \mathrm{~m}$ above the ground on four microclimates just outside the building showed a diversified heat gain risk. Microclimate on the North moved around $29^{\circ} \mathrm{C}-31{ }^{\circ} \mathrm{C}$, while West, South and East microclimates moved to peaks around $34{ }^{\circ} \mathrm{C}-41.5^{\circ} \mathrm{C}$ in the afternoon from 13.30 p.m. onwards. (Figure 10). This diversity can be attributed to the plan form and its orientation. Longer façades (points 1 and 5 on plan) of the main office spaces adjoining the atrium are exposed to direct solar access, a reason mainly attributable to form and orientation. It is interesting to understand that north microclimate was moving above east microclimate where direct solar access was available in the morning. North microclimate is on the wind shadow, close to the traffic and does not get any wind at all. 


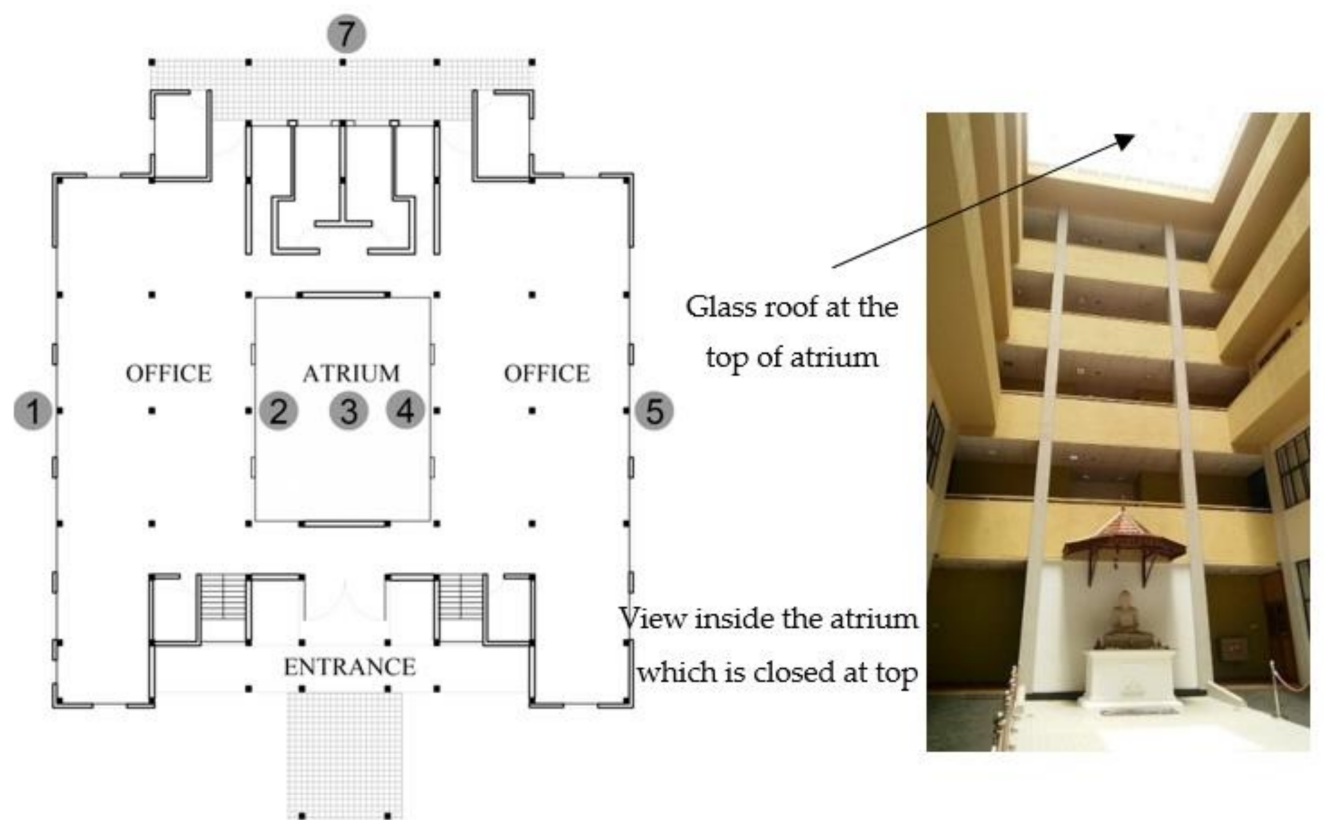

6

Glass roof at the top of atrium
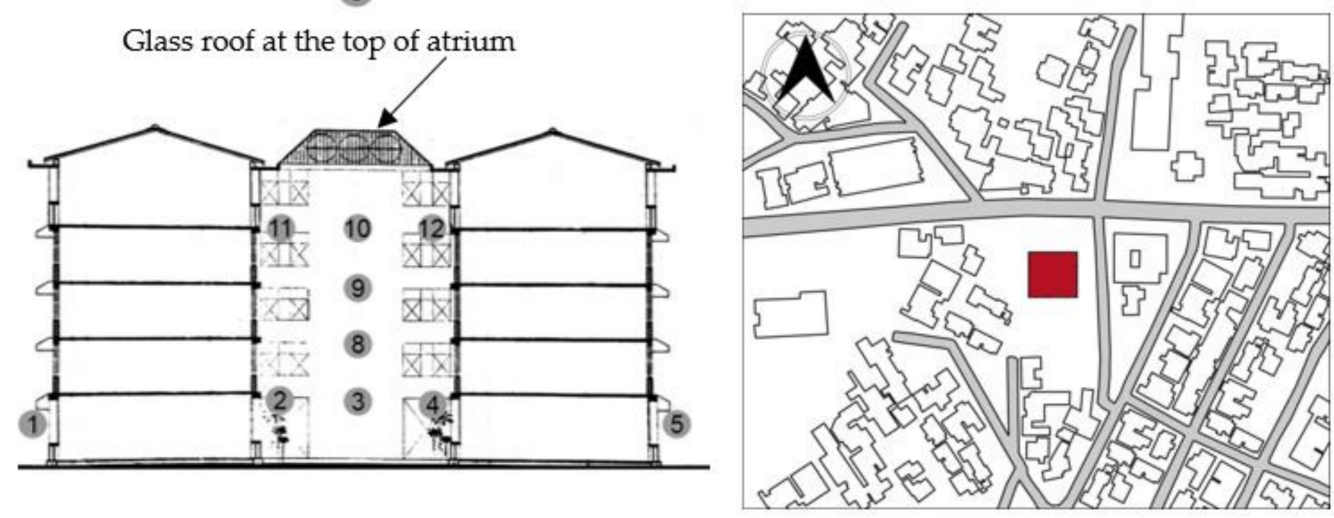

Figure 9. Building C (plan depth—25 $\mathrm{m}$, length—26 $\mathrm{m}$ ) Top left-Atrium plan form, Top right—Building in semi dense urban context, Bottom left-Section through the building with a central atrium.

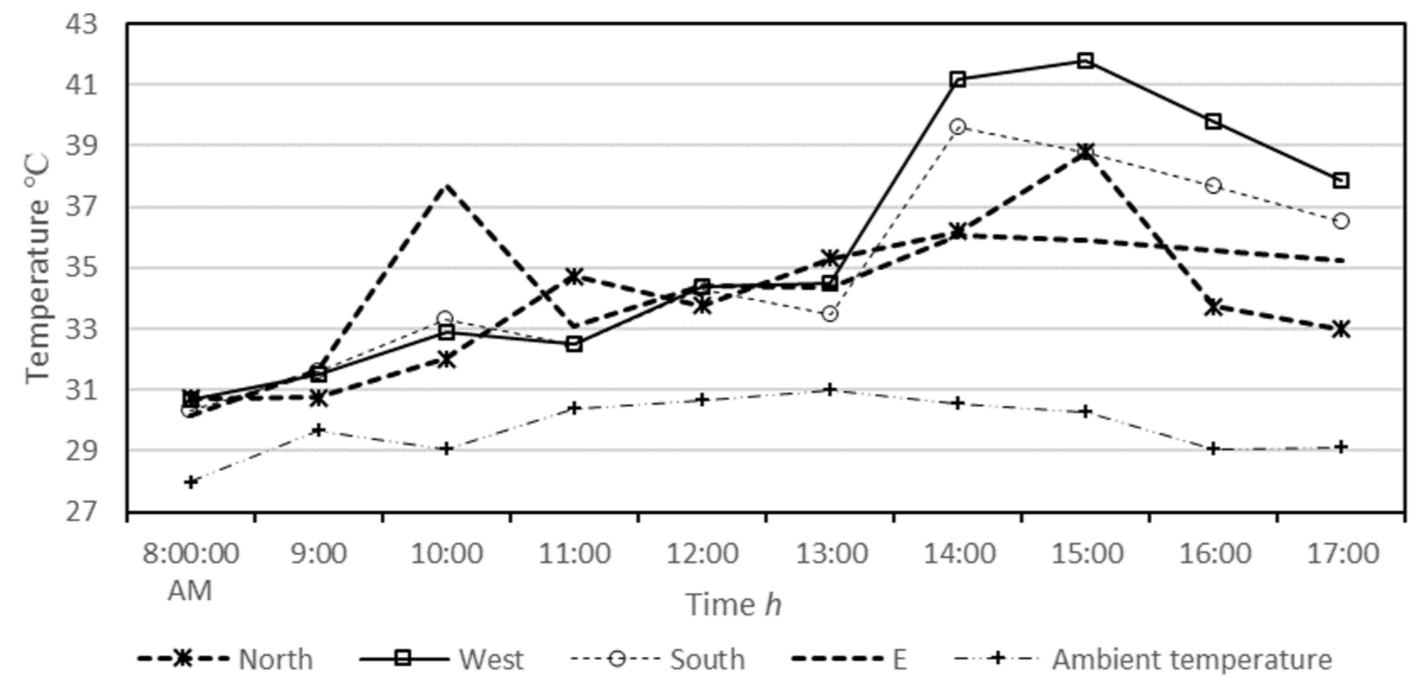

Figure 10. Heat gain risks on microclimates around the building with temperatures reaching $33{ }^{\circ} \mathrm{C}-38{ }^{\circ} \mathrm{C}$ in the morning on east and $35^{\circ} \mathrm{C}-42{ }^{\circ} \mathrm{C}$ in the afternoon on west. 
Figure 11 (below) shows a sharp increase of air temperature inside the atrium with its height in center during 09:00 a.m. and 14:00 p.m. Air temperature reached $36^{\circ} \mathrm{C}$ at $13.5 \mathrm{~m}$ level, $35^{\circ} \mathrm{C}$ at $10.5 \mathrm{~m}$, $33^{\circ} \mathrm{C}$ at $7.5 \mathrm{~m}$ and $4.5 \mathrm{~m}$ levels between 13:30-14:30 p.m. indicating an overheated situation of about $3.0^{\circ} \mathrm{C}-5.5^{\circ} \mathrm{C}$ above the ambient level. The air temperature started to decrease after 14:00 p.m. and entire thermal behavior followed the ambient pattern throughout the day and night. A stratification was not visible in the night instead overheating was visible and air temperature at all levels moved close to each other $2{ }^{\circ} \mathrm{C}-3{ }^{\circ} \mathrm{C}$ above the ambient temperature in the night. Results suggest direct heat gain from outside and roof level to the atrium, stagnation of internal heat inside and absence of night ventilation. The atrium is wrongly integrated into the building section hindering the capacity in heat removal, night ventilation and thus heat sink effect of thermal mass. This is a common mistake visible in most of building practices in Colombo.

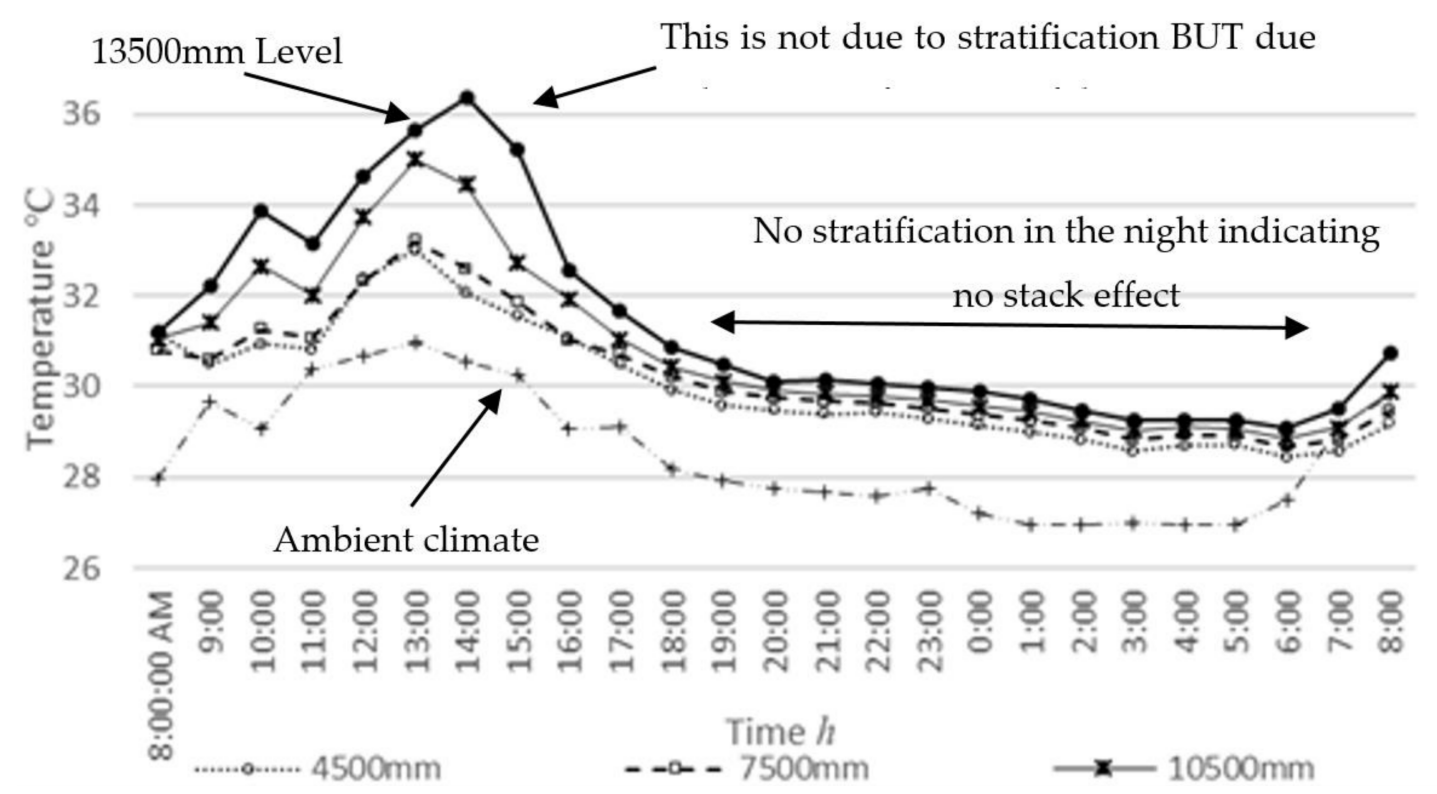

Figure 11. Vertical air temperature diversity in the atrium with its height up to $36.5^{\circ} \mathrm{C}$ from $29{ }^{\circ} \mathrm{C}$ and indoor overheating condition well above ambient in both day and night.

Air temperature behavior in the perimeter zone of the atrium, adjoining the occupied office spaces, was investigated to quantify the heat gain risk due to atrium of this building (Figure 12). Ground floor readings moved $1.5^{\circ} \mathrm{C}$ above the corresponding first floor level indicating higher heat gain risk at the ground level than the first floor level. Second floor and third floor level readings were moved $2{ }^{\circ} \mathrm{C}-2.5$ ${ }^{\circ} \mathrm{C}$ above the corresponding center of the atrium showing heat stress on the envelope dividing office spaces and atrium. Results indicate the risk of getting atriums overheated and their heat gain risks on adjacent occupies spaces. 


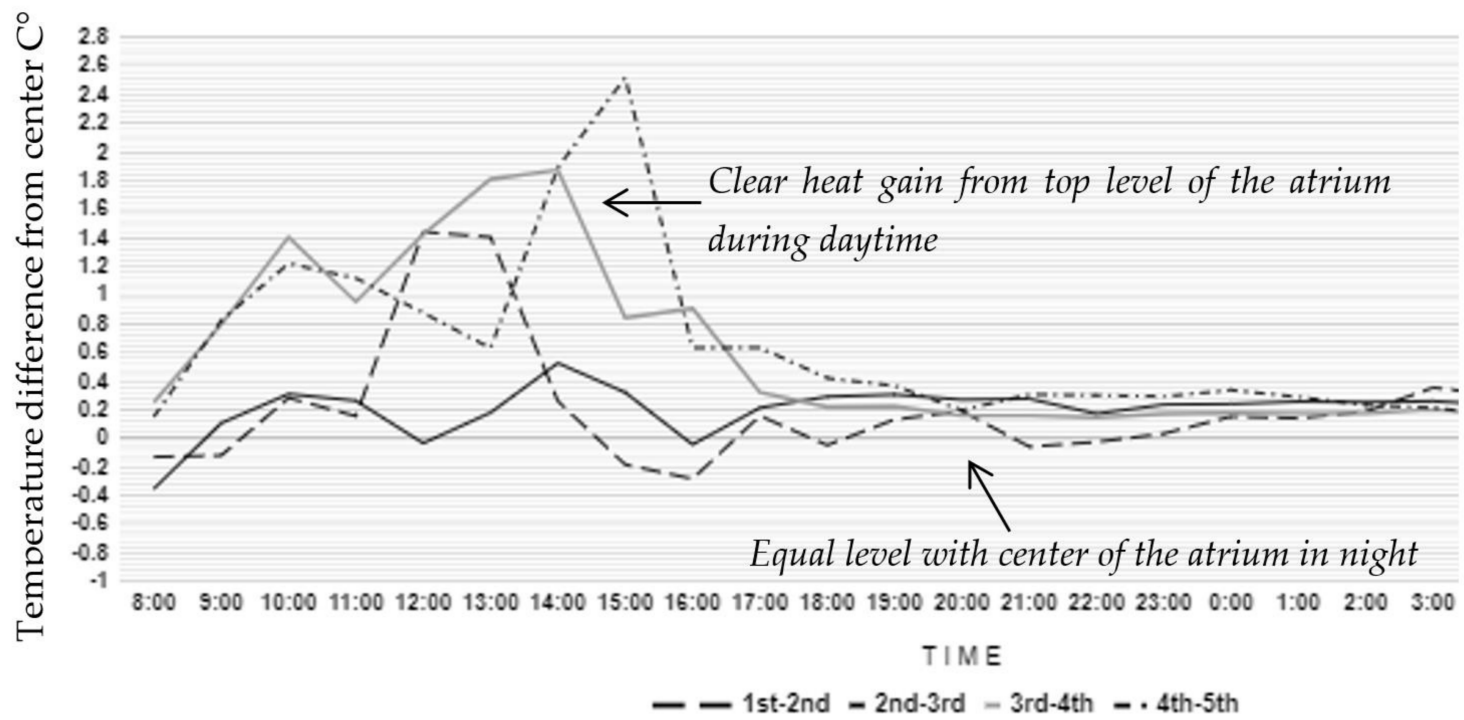

Figure 12. Elevation of air temperature in the perimeter zones of the atrium from its corresponding centers along 1st to 5 th floor levels creates a heat gain risk on the adjacent office spaces.

By monitoring the Building $C$ with a covered atrium, an attempt was made to predict a severity due to the heat stress scenario in closed atriums. Since closed atriums are commonplace in urban contexts in Colombo and other cities, future case versions of atrium buildings need to be thought carefully for the integration of interventions to avoid heat gain from outside and remove heat built up from indoors. There is evidence that high and prolonged periods of elevated temperatures in covered atriums could have a larger impact on surrounding occupied spaces in overheating than would be expected from a simple shallow or deep plan form in this research. This is due to the heat stress posed by a covered atrium in addition to the same from surrounding outer façades. It is therefore useful to understand not only the geometric considerations of atriums but also how and to what extent they interact with climate in imposing heat stress on indoors. Providing proper openings on the leeward side and at higher levels of the atrium could immensely benefit for a stack flow of air and removal of hot air.

\section{Decrement Delay}

The term Decrement delay in building design refers to the time the building takes for heat to pass through its outer façades and roofs to inside. This is quantified to be in delaying hours between the peak temperatures of the outside ambient climate or exterior surface of the building and the resulting temperature inside the building or of the internal surface of the façade. The decrement delay indicates an idea that thermal behavior of buildings with thermal mass is dynamic.

Decrement delays for the two buildings (A-shallow and B-deep) were calculated. With glazing percentage of the façades close to $50 \%$, and similar material characteristics in façades in both buildings, $\mathrm{A}$ and $\mathrm{B}$, a higher decrement delay of 4.5 was observed (Figure 13) from the ambient to the Center zone (C) despite the recorded diversities in maximum air temperatures occurred in ambient and indoor levels. It was noted during previous discussion that higher air temperatures were recorded in Center zone of the shallow form than the deep form meaning that heat dissipation rate inside shallow plan form is greater than in deep form. 


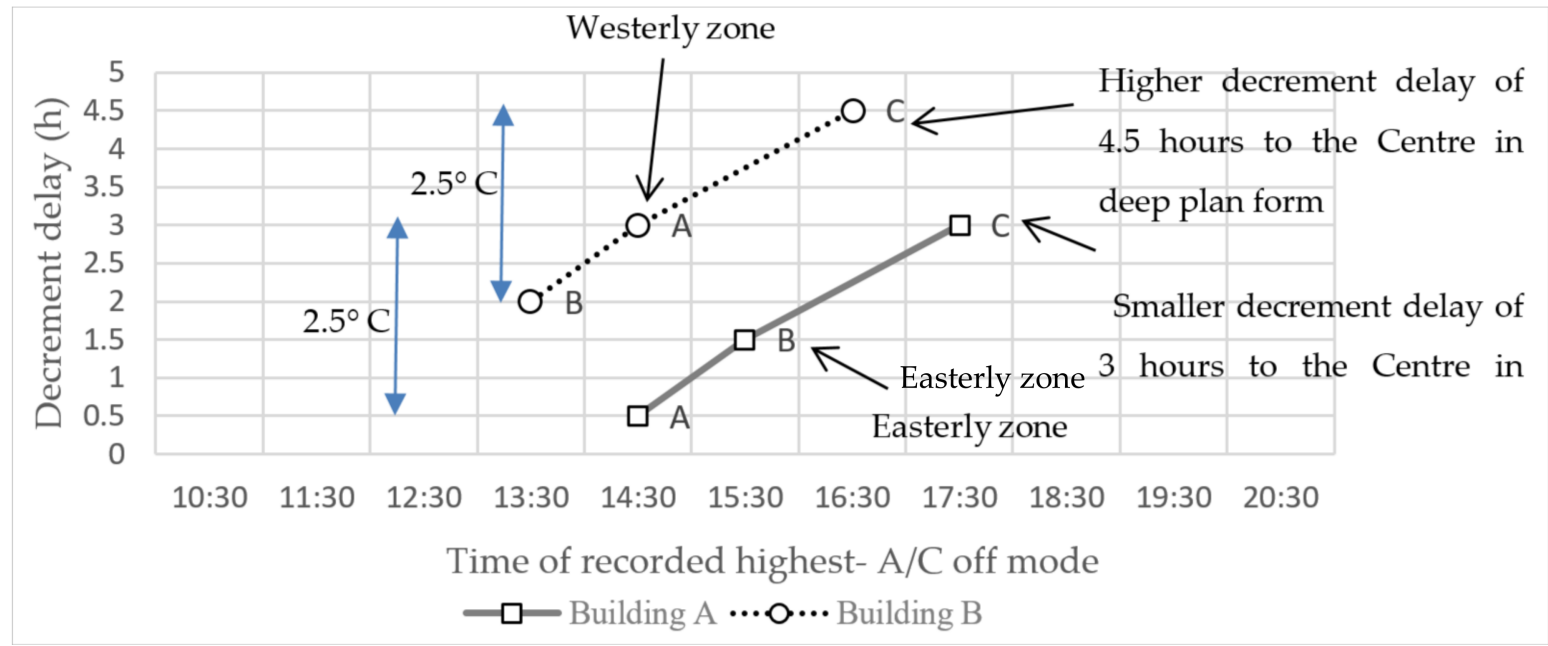

Figure 13. Equal decrement delays of air temperature from perimeter zones (A and B) to the Center (C) in shallow (Building A) and deep plan (Building B) forms in non-AC modes.

Despite higher and longer ambient air recorded with deep plan form Building B, decrement delay from average of internal peripheral zones to the Centre zone in both plan forms is $2.5 \mathrm{~h}$. Highest ambient range recorded with deep plan form was $34^{\circ} \mathrm{C}-36{ }^{\circ} \mathrm{C}$ for $7 \mathrm{~h}$ from $9: 30$ to $16: 30$ p.m. compared to the lesser values of highest ambient range and its duration in shallow plan form Building $\mathrm{A}$, where highest ambient range was $34^{\circ} \mathrm{C}-35^{\circ} \mathrm{C}$ for just $3 \mathrm{~h}$ from $13: 30$ to $16: 30 \mathrm{p}$.m.-meaning that deep plan form has worked effectively in delaying heat stress to the Center. The outcome suggests a potential of deep plan forms in addressing heat stress from outside.

Decrement delay in the internal surface of the façade in deep plan form close to the peripheral zones $\mathrm{A}$ and $\mathrm{B}$ is $3.5 \mathrm{~h}$ from the highest ambient record whereas the internal surface in shallow form has a shorter decrement delay of $1.5 \mathrm{~h}$. Since façade materials and glazing proportions of both forms are of the same kind, the results indicate that the higher average indoor air temperature due direct heat gain through façades could be a contributing factor for this behavior. This concern however, needs a more detailed investigation. Shorter decrement delay in shallow plan forms indicates a disadvantageous situation in addressing heat stress from outside (Figure 14).

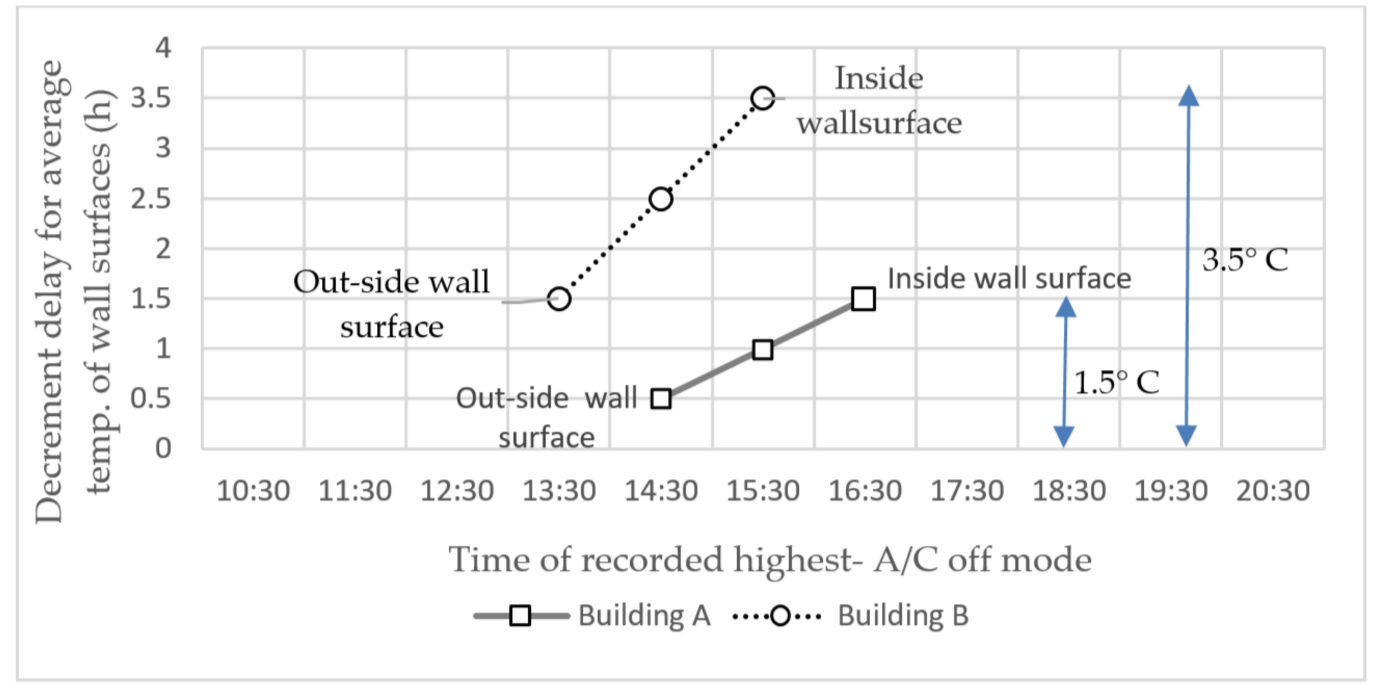

Figure 14. Shorter decrement delay of $1.5^{\circ} \mathrm{C}$ with inside wall surface temperature in shallow plan form (Building A) as compared to the larger decrement delay of $3.5^{\circ} \mathrm{C}$ with the same in deep plan form (Building B). 
The average decrement delay along the height in atrium was just $1.5 \mathrm{~h}$-meaning that covered atriums could be problematic in addressing environmental heat stress. Increase of decrement delays during the daytime along the height shows a thermal stratification due to direct heat gain but any air flow moment cannot be predicted due to the complete closure of the atrium at the top (Figure 15). This stagnation of heat stress and its behavior inside the atrium can be used to show the need to have a heat removal method in atrium form buildings, a major driver in addressing heat stress. More research involving a larger population of atrium buildings with varied plan forms is expected to be carried out.

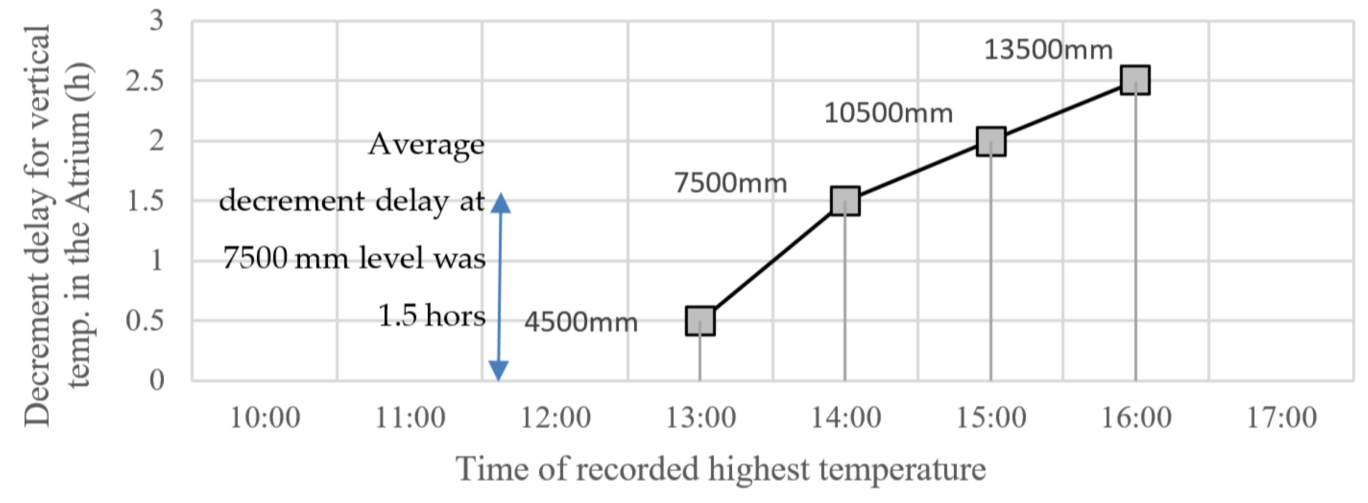

Figure 15. Decrement delay inside the covered atrium in Building $C$ at different vertical levels.

\section{Conclusions}

Despite growing need to avoid indoor overheating due to environmental heat stress, a lack of evidence exists on the scale of the problem in air-conditioned office buildings in tropics. The research analyzed a high prevalence of heat stress in contemporary office building types in Colombo, indicating the need to understand the plan depth as an important design consideration in dispersing the indoor air temperature due to heat stress through building façades.

The aim of the research was to question the impact of plan depth of multi-level office buildings in tropics in minimizing the elevation of indoor air temperature due to heat stress on the façades. The current body of knowledge which is less supportive for professionals working in urban office building sector and minimum performance standards, particularly in Sri Lanka, do not meaningfully address the issue of heat stress on façades.

From the investigated cases, shallow plan, deep square and deep plan with a closed atrium with a glass roof, it is evident that indoor air temperature distribution in deep plan forms are more favorable in respect to controlling heat stress coming from outside or dispersing the heat across a plan depth. Findings suggested a distribution of relatively lower air temperatures in deep plan forms than in shallow plan forms. This was evident when buildings investigated were in non-air conditioned modes indicating relatively less heat stress situations in deep plan air conditioned buildings in tropics.

Warm climates in tropics with urbanization and dense built mass create more devastating heat gain risks on buildings. An appropriate bio-climatic influence in the building design is required to build resilience to the impacts of heat gain risks even on air-conditioned buildings. The literature that the research evidences are based on is still limited in breath, for tropics in particular. Manipulating plan depth for reducing heat stress in peripheral zones and thus across the entire plan depth could be a promising and supportive initiative in bio-climatic design as well.

Even accounting for fundamental issues like global warming, heat island effects and urbanization, the man parameters causing overheating due to heat stress appear to be those relating to building design itself. Heat gain risk assessment is required for designing adaptive and climate responsive design, and it needs to be emphasized in building regulations in countries with severe warming climates. Based on the results, a method, using the range of indoor air temperature elevation above the corresponding ambient levels during air-conditioning off-mode, to assess heat gain risks can be 
useful as a simple method for assessing the existence of heat stress problems of existing buildings, including air-conditioned environments. For new building proposals, simulation programs could be developed. For more accurate assessments and predictions multi-zone method is more appropriate to estimate the heat gain risk in real situations, because it can take account of thermal dynamics of the building form, occupancy, lighting and heat dissipation between zones. Use of covered atriums and unprotected façades will create heat stress on indoor spaces due to direct environmental loads from glass atrium roofs and indirect internal gains as well. Considerations of integrating cool atriums with buildings for internal heat removal, night ventilation and heat sink effect of thermal mass is left for future research. These performance evidence are expected to be further validated though an extended field investigation to continue on the same direction of thinking with a long term duration for at least 6 months with larger samples representing a variety of buildings.

Restrictions on land size due to urbanization have led to an increase in compact sallow plan forms with walls made of thermally light-weight materials. Most contemporary buildings have lower ceiling heights and large windows to have a modern glassy appearance. With security concerns, urban air pollution and traffic noise, architects and occupants often tend to render buildings with sealed façades limiting the potential for heat removal from indoors even with atrium buildings. The current monitored experiments of this work clearly support the general level at which current heat stress threshold on building façades and indoors are visible. Although they cannot pass judgement on the veracity of the heat stress threshold for use in any commercial building, results do clearly show the very wide range of conditions with regard to plan form depth over which heat stress on indoor is visible. The work highlights lessons on the ways that plan form can interfere in addressing heat stress from outside.

\section{Limitations and Strengths}

Factors other than building envelope, plan form and orientation can influence climate interaction of buildings. The factors include, but not limited to structural components like floor and column system, space lighting systems, occupancy pattern which were not considered due to similarity in physical properties and behavior. The case study approach used in this work depends only on 12 buildings initially and then on three for detailed investigations. However, the methodology of the research could be contended to offer generalizing the findings. The outcome implies that application of fundamentals arising from the observed data could be appropriate and integrated to similar other buildings within the same climatic and urban contexts. This is justifiable because of the similar and related building typologies, environments and occupancy patterns in which the buildings operate.

During the data collection, analysis and presentation names and locations of buildings remained anonymous respecting the owners, occupants and participants of the research as suggested by Creswell [52].

Author Contributions: The author is responsible for the the entire research involving literature review, investigation plan, outcome analysis and conclusions.

Funding: The research was partially supported by a National Research Council (NRC) Grant 13-109 of Sri Lanka by giving funding for purchasing equipment.

Acknowledgments: Author acknowledges the support given by H.W.K. Jayathilake and W.S. Jayasinghe in data collection in the field investigations.

Conflicts of Interest: The author declares no conflicts of interest.

\section{References}

1. Santamouris, M.; Balaras, C.A.; Dascalaki, E.; Argiriou, A.; Gaglia, A. Energy conservation and retrofitting potential in Helenic hotels. Energy Build. 1996, 24, 1-83. [CrossRef]

2. Santamouris, M.; Kolokotsa, D. Passive cooling dissipation techniques for buildings and other structures: The state of the art Review Article. Energy Build. 2013, 57, 74-94. [CrossRef] 
3. Szokolay, S.V. Introduction to Architectural Science: The Basis of Sustainable Design; Architectural Press: Hudson, New York, NY, USA; Elsevier: Amsterdam, The Netherlands, 2005.

4. Santamouris, M. Advances in Passive Cooling; Earthscan Publishers: London, UK, 2006.

5. Yau, Y.H.; Hasbi, S. A review of climate change impacts on commercial buildings and their technical services in the tropics. Renew. Sustain. Energy Rev. 2013, 18, 430-441. [CrossRef]

6. IPCC. Climate Change 2014: Synthesis Report. Contribution of Working Groups I, II and III to the Fifth Assessment Report of the Intergovernmental Panel on Climate Change; Core Writing Team, Pachauri, R.K., Meyer, L.A., Eds.; IPCC: Geneva, Switzerland, 2014.

7. Coley, D.; Kershaw, T. Changes in internal temperatures within the built environment as a response to a climate change. Build. Environ. 2010, 45, 89-93. [CrossRef]

8. Howden, S.M. Effect of climate and climate change on electricity demand in Australia. In Integrating Models for Natural Resources Management Across Discipline, Issue and Scale; Ghassemi, F., Whetton, P., Little, R., Littleboy, M., Eds.; MSSANZ Inc.: Canberra, Australia, 2001; pp. 655-660.

9. Guan, L. Implication of global warming on Air-Conditioned office buildings in Australia. Build Res. Inf. 2009, 37, 43-54. [CrossRef]

10. Garnaut, R. The Garnaut Climate Change Review, Final Report; The Cambridge University Press: Cambridge, UK, 2008.

11. Radhi, H. Can envelope codes reduce electricity and $\mathrm{CO} 2$ emissions in different types of buildings in the hot climate of Bahrain? Energy 2009, 34, 205-215. [CrossRef]

12. Santamouris, M.; Asimakopoulos, D. Passive Cooling of Buildings; Earthscan Publishers: London, UK, 2006.

13. Givoni, B. Effectiveness of mass and night ventilation in lowering the indoor daytime temperatures. Energy Build. 1998, 28, 25-32.

14. Givoni, B. Indoor temperature reduction by passive cooling systems. Sol. Energy 2011, 85, 1692-1726. [CrossRef]

15. Rajapaksha, U.; Gunesekara, A.; Rajapaksha, I.; Hyde, R. Developing a conceptual model for passive cooling in buildings in the tropics: a case study of Maritime Museum Galle, Sri Lanka. Proceeding of 48th Conference of Architectural Science Association, Genoa, Italy, 10-13 December 2014; Madeo, F., Novi, E., Eds.; pp. 581-592.

16. Rajapaksha, I.; Nagai, H.; Okumiya, M. A ventilated courtyard as a passive cooling strategy in warm humid tropics. Renew. Energy 2003, 28, 1755-1778. [CrossRef]

17. Aynsley, R.; Shiel, J.J. Ventilation strategies for a warming world. Archit. Sci. Rev. 2017, 60, $249-254$. [CrossRef]

18. Szokolay, S.V. PLEA Notes. In Thermal Comfort; The University of Queensland: Brisbane, Austrilia, 1997.

19. Voss, K.; Herkel, S.; Pfafferott, J.; Lohnert, G.; Wagner, A. Energy efficient office buildings with passive cooling-Results and experiences from a research and demonstration programme. Sol. Energy 2007, 81, 424-434. [CrossRef]

20. Lam, J. Energy analysis of commercial buildings in subtropical climates. Build. Environ. 2000, 35, 19-26. [CrossRef]

21. Sanchez, E.; Rolandoa, A.; Sant, R.; Ayuso, L. Influence of natural ventilation due to buoyancy and heat transfer in the energy efficiency of a double skin facade building. Energy Sustain. Dev. 2016, 33, 139-148. [CrossRef]

22. Barbosa, S.; Kenneth, I. Perspectives of double skin façades for naturally ventilated buildings: A review. Renew. Sustain. Energy Rev. 2014, 40, 1019-1029. [CrossRef]

23. Valladares-Rendón, L.G.; Schmid, G.; Lo, S. L. Review on energy savings by solar control techniques and optimal building orientation for the strategic placement of façade shading systems. Energy Build. 2017, 140, 458-479. [CrossRef]

24. Carmen, A.; Fernando, M.-C.; Ignacio, O.; Eloy, A.; Gloria, P.; Isabel, M. Effect of façade surface finish on building energy rehabilitation. Sol. Energy 2017, 146, 470-483.

25. Prieto, A.; Ulrich, K.; Tillmann, K.; Thomas, A. 25 Years of cooling research in office buildings: Review for the integration of cooling strategies into the building façade (1990-2014). Renew. Sustain. Energy Rev. 2017, 71, 89-102. [CrossRef] 
26. Halawa, E.; Ghaffarianhoseini, A.; Ghaffarianhoseini, A.; Trombley, J.; Hassan, N.; Baig, M.; Yusoff, S.Y.; Ismail, M.A. A review on energy conscious designs of building façades in hot and humid climates: Lessons for (and from) Kuala Lumpur and Darwin. Renew. Sustain. Energy Rev. 2018, 82, 2147-2161. [CrossRef]

27. Yong, S.; Kim, J.; Gim, Y.; Kim, J.; Cho, J.; Hong, H.; Baik, Y.; Koo, J. Impacts of building envelope design factors upon energy loads and their optimization in US standard climate zones using experimental design. Energy Build. 2017, 141, 1-15. [CrossRef]

28. Mirrahimi, S.; Mohamed, M.F.; Haw, L.C.; Ibrahim, N.L.N.; Yusoff, W.M.F.; Aflaki, A. The effect of building envelope on the thermal comfort and energy saving for high-rise buildings in hot-humid climate. Renew. Sustain. Energy Rev. 2016, 53, 1508-1519. [CrossRef]

29. Friess, W.A.; Rakhshan, K. A review of passive envelope measures for improved building energy efficiency in the UAE. Renew. Sustain. Energy Rev. 2017, 72, 485-496. [CrossRef]

30. Bui, V.P.; Liu, H.Z.; Low, Y.Y.; Tang, T.; Zhu, Q.; Shah, K.W.; Shidoji, E.; Lim, Y.M.; Koh, W.S. Evaluation of building glass performance metrics for the tropical climate. Energy Build. 2017, 157, 195-203. [CrossRef]

31. Lei, J.; Yang, J.; Yang, E. Energy performance of building envelopes integrated with phase change materials for cooling load reduction in tropical Singapore. Appl. Energy 2016, 162, 207-217. [CrossRef]

32. Fathoni, A.M.; Chaiwiwatworakul, P.; Mettanant, V. Energy analysis of the day lighting from a double-pane glazed window with enclosed horizontal slats in the tropics. Energy Build. 2016, 128, 413-430. [CrossRef]

33. Auliciems, A. Global differences in indoor thermal differences requirements. In Proceedings of the 51st Conference of the Australian and New Zealand Association for the Advancement of Science, Brisbane, Australia, 11-15 May 1981.

34. ASHRAE. ANS/ASHRAE/IESStandards 90.1-2010 Performance Rating Method Reference Manual; Pacific Northwest National Lab.: Richland, WA, USA, 2016.

35. Nicol, J.F.; Humphreys, M.A. Derivation of the Adaptive Equations for Thermal Comfort in Free-Running Buildings in European Standard EN15251. Build. Environ. 2010, 45, 11-17. [CrossRef]

36. Brotas, L.; Nicol, F. Estimating overheating in European dwellings. Archit. Sci. Rev. 2017, 60, $180-191$. [CrossRef]

37. Vellei, M.; Alfonso, P.; Ramallo-González; Coley, D.; Lee, J.; Gabe-Thomas, E.; Lovett, T.; Natarajan, S. Overheating in vulnerable and non-vulnerable households. Build. Res. Inf. 2017, 45, 102-118. [CrossRef]

38. Emmanuel, R. Performance standard for tropical outdoors: A critique of current impasse and a proposal for way forward. Urban Clim. 2018, 23, 250-259. [CrossRef]

39. Olgyay, V.; Olgyay, A. Design with Climate: Bio-Climatic Approach to Architectural Regionalism; Princeton University Press: Princeton, NJ, USA, 1963.

40. Hyde, R. Climate Responsive Design: A Study of Buildings in Moderate and Hot Humid Climates; E and FN Spon: London, UK, 2000.

41. Roaf, S. Ecohouse 2: A Design Guide; Architectural Press: Hudson, NY, USA, 2003.

42. Hawkes, D. The Environmental Tradition: Studies in the Architecture of Environment; E\&FN Spon: London, UK, 1996; 212p.

43. Gokhale, M. Between the building and the macroclimate. In Proceedings of the 31st International ANZAScA Conference, Principles and Practice, The University of Queensland, Brisbane, Australia, 29 September-3 October 1997; pp. 27-39.

44. Amos-A, S.; Akuffo, F.O.; Kutin-Sanwu, V. Effects of Thermal Mass, Window Size, and Night-Time Ventilation on Peak Indoor Air Temperature in the Warm-Humid Climate of Ghana. Sci. World J. 2013, 2013, 1-9. [CrossRef]

45. Md Mohataz, H.; Lau, B.; Wilson, R.; Ford, B. Effect of changing window type and ventilation strategy on indoor thermal environment of existing garment factories in Bangladesh. Archit. Sci. Rev. 2017, 60, $299-315$. [CrossRef]

46. Rajapaksha, U.; Rupasinghe, H.T; and Rajapaksha, I. Resolved duality: external double skin envelopes for energy sustainability of office buildings in the tropics. Proceedings of 31st International Conference of Passive and Low Energy Architecture Conference, Bologna, Italy, 9-11 September 2015.

47. Amarathunga, A.A.N.D.; Rajapaksha, U. A critical review on high rise buildings in the context of bio-climatic design: A case of vertical diversity in Tropical Colombo. In Proceedings of the 9th International Research Conference of FARU Building the Future -sustainable and resilient environments, Colombo, Sri Lanka, 9-10 September 2016; Rajapaksha, U., Ed.; pp. 425-439. 
48. ECG19. Energy Consumption Guide: Energy Use in Offices. 2003. Available online: http:www.cibse.org (accessed on 9 September 2019).

49. Rajapaksha, U. Heat stress pattern in conditioned office buildings with shallow plan forms in Metropolitan Colombo. Buildings 2019, 9, 35. [CrossRef]

50. Simson, R.; Kurnitski, J.; Kuusk, K. Experimental validation of simulation and measurement-based overheating assessment approaches for residential buildings. Archit. Sci. Rev. 2017, 60, 192-204. [CrossRef]

51. CMC. Engineers Department Data; Colombo Municipal Council: Colombo, Sri Lanka, 2017.

52. Creswell, J.W. Research Design: Qualitative, Quantitative, and Mixed Method Approaches, 3rd ed.; Sage: Thousand Oaks, CA, USA, 2009.

(C) 2020 by the author. Licensee MDPI, Basel, Switzerland. This article is an open access article distributed under the terms and conditions of the Creative Commons Attribution (CC BY) license (http://creativecommons.org/licenses/by/4.0/). 